Maria Célia Calijuri Hamra

\title{
Câncer colorretal localmente avançado : resultados do tratamento cirúrgico e fatores prognósticos
}

Dissertação apresentada à Faculdade de Medicina da Universidade de São Paulo para obtenção do título de Mestre em Ciências

Área de concentração: Cirurgia do Aparelho Digestivo

Orientador: Prof. Dr. Fábio Guilherme Caserta Maryssael de Campos

SÃO PAULO

2009 
Dados Internacionais de Catalogação na Publicação (CIP)

Preparada pela Biblioteca da

Faculdade de Medicina da Universidade de São Paulo

Creprodução autorizada pelo autor

Hamra, Maria Célia Calijuri

Câncer colorretal localmente avançado: resultados do tratamento cirúrgico e fatores prognósticos / Maria Célia Calijuri Hamra. -- São Paulo, 2009.

Dissertação (mestrado)--Faculdade de Medicina da Universidade de São Paulo.

Departamento de Gastroenterologia.

Área de concentração: Cirurgia do Aparelho Digestivo.

Orientador: Fábio Guilherme Caserta Maryssael de Campos.

Descritores: 1.Neoplasias colorretais/cirurgia 2.Prognóstico 3.Avanço da doença 4.Análise de sobrevida

USP/FM/SBD-001/09 
Dedico esta dissertação aos meus pais, José (in memorian) e Carmen, que são a razão da minha existência e nos quais sempre me inspirei. 


\section{Agradecimentos}

Agradeço a minha família: Samir, meu marido, e aos meus filhos Samir Neto, José Eduardo e Isabela, pela compreensão e paciência.

Aos meus pais, José (in memorian) e Carmen, pela educação.

Às minhas irmãs, Maria Lúcia e Maria do Carmo, pelo apoio e incentivo.

Ao meu orientador, Prof. Dr. Fábio Guilherme Campos, pelo aprendizado e pela disponibilidade.

Ao Prof. Dr. Desidério R. Kiss, pela oportunidade de desenvolver esse trabalho.

Ao Prof. Dr. Ivan Cecconello, pela confiança.

Aos professores da Banca de Qualificação, Prof. Dr. Sérgio Nahas, Prof. Dr. José Eduardo M. Cunha e Prof. Dr. Wilmar Artur Klug, pelas críticas que enriqueceram este trabalho.

Aos estatísticos Camila e Démerson, pela colaboração.

Também às secretárias do departamento e amigos, pela cumplicidade.

À Vera, minha secretária particular, pelo convívio diário, pela dedicação com que organiza minha agenda e o carinho com meus pacientes. 


\section{Normalização adotada}

Esta dissertação está de acordo com as seguintes normas, em vigor no momento desta publicação:

Referências: adaptadas do International Committee of Medical Journals Editors (Vancouver)

Universidade de São Paulo. Faculdade de Medicina. Serviço de Biblioteca e Documentação. Guia de apresentação de dissertações, teses e monografias. Elaborado por Anneliese Carneiro da Cunha, Maria Júlia de A. L. Freddi, Maria F. Crestana, Marinalva de Souza Aragão, Suely Campos Cardoso, Valéria Vilhena. $2^{a}$ Ed. São Paulo: Serviço de Biblioteca e Documentação; $2005^{1}$.

Abreviaturas dos títulos dos periódicos de acordo com List of Journals Indexed in Index Medicus. 


\section{Sumário}

Lista de Abreviaturas ............................................................. viii

Lista de Siglas ......................................................................... ix

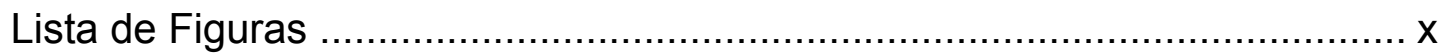

Lista de Tabelas ...............................................................................

Resumo ..................................................................................... xii



1 Introdução.................................................................................. 1

1.1 Importância do assunto.......................................................... 2

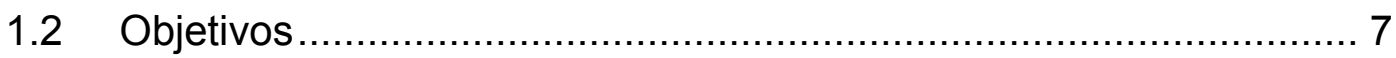



2.1 Caracterização da casuística ................................................... 9

2.2 Levantamento de dados .................................................... 10

2.3 Análise estatística ........................................................... 12

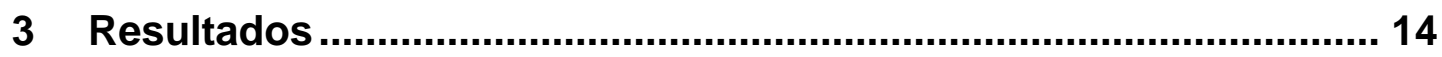

3.1 Sexo, idade e localização do tumor primário ............................ 15

3.2 Das operações realizadas ............................................... 18

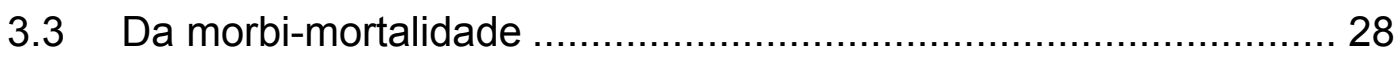

3.4 Das características tumorais ......................................... 30



4 Discussão ............................................................................. 53



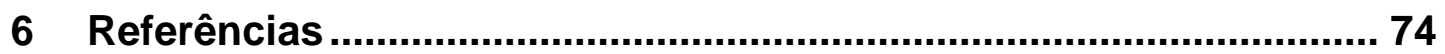


Listas 


\section{Lista de Abreviaturas}

$\begin{array}{ll}\text { BOXPLOT } & \text { Representação gráfica quantitativa } \\ \text { CCR } & \text { Câncer colorretal } \\ \text { Dr. } & \text { Doutor } \\ \text { ed. } & \text { Editora } \\ \text { et al. } & \text { e colaboradores } \\ \text { Fac. } & \text { Faculdade } \\ \text { Hosp. } & \text { Hospital } \\ \text { p. } & \text { Páginas } \\ \text { Prof. } & \text { Professor } \\ \text { vs. } & \text { Versus }\end{array}$




\title{
Lista de Siglas
}

\author{
ABNT Associação Brasileira de Normas Técnicas \\ AJCC American Joint Committee on Cancer \\ $\mathrm{JNCl} \quad$ Journal National Cancer Institute \\ USP Universidade de São Paulo \\ PAF Polipose Adenomatosa Familiar \\ HNPCC Hereditary Non Polyposis Colorectal Cancer \\ UICC União Internacional Contra o Câncer
}




\section{Lista de Figuras}

Figura 1: Distribuição da localização dos tumores em relação ao sexo.......16

Figura 2: Colectomia total + enterectomia segmentar + colecistectomia .....21

Figura 3: Localização do tumor primário no ângulo hepático

Figura 4: Amputação abdominoperineal do reto com cistectomia total e reimplante ureteral (neoplasia do reto com invasão da bexiga)

Figura 5: Amputação abdominoperineal do reto e cistectomia total. .23

Figura 6: Ressecção de parte da parede lateral esquerda do abdome 24

Figura 7: Sigmóide + parte da parede lateral esquerda do abdome 24

Figura 8: Tomografia computadorizada da pelve mostrando invasão da bexiga por um tumor primário do reto

Figura 9: Porcentagem de órgãos ressecados em monobloco, aderidos ao tumor primário

Figura 10: Distribuição da porcentagem dos pacientes que foram transfundidos

Figura 11: Distribuição da porcentagem de transfusão sangüínea em relação ao sexo.

Figura 12: Distribuição da porcentagem do tipo histológico.

Figura 13: Grau de diferenciação.

Figura 14: Distribuição do comprometimento ganglionar .

Figura 15: Presença ou não de algum tipo de invasão

Figura 16: Sobrevivência estimada comparando a profundidade do tumor (T3 vs. T4)

Figura 17: BOXPLOT do tempo de sobrevivência em relação à profundidade do tumor. 
Figura 18: Sobrevivência estimada considerando a ausência ou presença de linfonodos comprometidos

Figura 19: BOXPLOT do tempo de sobrevivência em relação à existência de linfonodos comprometidos

Figura 20: Sobrevivência estimada considerando a ausência ou a presença de invasão vascular, linfática e perineural.

Figura 21: BOXPLOT do tempo de sobrevivência em relação à variável invasão

Figura 22: Sobrevivência estimada considerando a variável local do tumor: cólon vs. reto

Figura 23: BOXPLOT do tempo de sobrevivência em relação ao local do tumor.

Figura 24: Sobrevida em relação à aderência inflamatória vs. aderência neoplásica

Figura 25: Sobrevida em relação à realização ou não de transfusão sangüínea

Figura 26: Sobrevida em relação à quantidade de unidades de sangue transfundidas

Figura 27: Sobrevida em relação ao número de órgãos ressecados junto com o tumor primário

Figura 28: Sobrevida em relação ao grau de diferenciação (bem diferenciado vs. moderadamente diferenciado vs. pouco diferenciado)

Figura 29: Sobrevida em relação ao tipo histológico (adenoma tubular vs. túbulo viloso vs. epitelial). .50

Figura 30: Sobrevida global estimada (em meses) 


\section{Lista de Tabelas}

Tabela 1: Média de idade e variações ............................................ 15

Tabela 2: Sexo e localização dos tumores ...................................... 16

Tabela 3: Sexo e locais do tumor primário...................................... 17

Tabela 4: Procedimentos cirúrgicos principais..................................... 19

Tabela 5: Freqüência dos órgãos ressecados em bloco......................... 20

Tabela 6: Causas de morbidade operatória ......................................... 29

Tabela 7: Distribuição das invasões vascular, linfática e perineural ......... 34

Tabela 8: Freqüência da invasão linfática vs. penetração do tumor ......... 35

Tabela 9: Freqüência de T3 e T4 por número de órgãos comprometidos 36

Tabela 10: Freqüência da localização das recidivas ............................ 37

Tabela 11: Relação das variáveis que não influenciaram a sobrevida ....... 45

Tabela 12: Variáveis que interferiram na sobrevida de cinco anos............ 52 


\section{Resumo}

Calijuri-Hamra MC. Câncer colorretal localmente avançado: resultados do tratamento cirúrgico e fatores prognósticos [dissertação]. São Paulo: Faculdade de Medicina, Universidade de São Paulo; 2009. 86p.

Introdução: O Câncer Colorretal (CCR) localmente avançado é caracterizado pela aderência ou invasão do tumor primário a órgãos ou estruturas vizinhas. Nesses pacientes, a realização de cirurgia alargada por meio de ressecção multivisceral em bloco constitui a melhor alternativa para prover perspectivas de cura. Os objetivos desse estudo foram estimar a incidência das lesões localmente avançadas em nosso meio, avaliar os resultados operatórios e investigar os fatores que influenciaram $o$ prognóstico. Pacientes e Métodos: realizou-se estudo coorte retrospectivo incluindo 679 pacientes com CCR que foram submetidos a tratamento cirúrgico entre 1995 a 2007. Foram anotados dados clínicos (idade, sexo e co-morbidades), cirúrgicos e histológicos (localização da neoplasia, órgãos adjacentes comprometidos e disseminação tumoral) dos pacientes portadores de neoplasia colorretal localmente avançada. Os índices de sobrevida foram estimados pela curva de Kaplan - Meier considerando apenas os doentes que foram submetidos à operações com intenção curativa. Resultados: 90 pacientes $(13,2 \%)$ com tumor localmente avançado foram identificados. A idade média foi de 59 anos e houve predomínio no sexo feminino (61\%). A distribuição topográfica demonstrou que $66 \%$ dos tumores localizavam-se no cólon e $34 \%$ no reto. A distribuição quanto ao sexo revelou maior prevalência dos tumores retais entre as mulheres $(77 \%$; $p=0,02$ ). Complicações no pós-operatório foram registradas em $25,6 \%$ dos doentes, representados principalmente por deiscência e/ou infecção da parede abdominal (22\%), íleo prolongado (14,8\%) e deiscência de anastomose $(11,1 \%)$. A mortalidade peri-operatória foi de $3,3 \%$. Os órgãos mais freqüentemente envolvidos foram o intestino delgado $(19,9 \%)$, bexiga $(16,4 \%)$ e útero $(12,9 \%)$. Quanto à penetração tumoral, foram detectadas lesões T4 em $58 \%$ e lesões T3 em $42 \%$. A sobrevida de 5 anos foi menor entre os tumores T4 em relação às lesões T3 (50\% vs. $75 \%$; $p=0,01)$. Em média, 21,6 linfonodos ( $(\mathrm{LN})$ foram ressecados durante os procedimentos e o envolvimento linfonodal pela neoplasia determinou sobrevida menor $(35 \%$ $\mathrm{LN}+$ vs. $80 \% \mathrm{LN}$-; $\mathrm{p}=0,004)$. Observou-se também redução dos índices de sobrevida associados a outros fatores como a presença da invasão vascular, linfática e perineural ( $35 \%$ vs. $80 \%$; $p=0,02$ ), e localização retal dos tumores quando comparada às lesões colônicas $(45 \%$ vs. $65 \%$; $p=0,01)$. Por outro lado, o caráter neoplásico (59\%) ou inflamatório $(41 \%)$ das aderências não influenciou significativamente os índices de sobrevida (55\% vs. $65 \%$, 
$\mathrm{p}=0,60)$. Conclusão: 1) durante o período de estudo, detectaram-se lesões localmente avançadas em 13,2\% dos pacientes; 2) ocorreram complicações operatórias em $25 \%$ dos procedimentos; 3) a sobrevida dos pacientes submetidos a operações com intenção curativa sofreu impacto negativo na presença de maior penetração na parede, invasão vascular, linfática e perineural, nos tumores de localização retal e naqueles com linfonodos comprometidos; 4) outras variáveis como tipo histológico, grau de diferenciação tumoral, número de órgãos ressecados, transfusão de sangue e caráter das aderências entre órgãos não influenciaram as chances de sobrevida.

Descritores: Neoplasias colorretais, prognóstico, avanço da doença, análise de sobrevida. 


\section{Summary}

Calijuri-Hamra MC. Locally Advanced Colorectal Cancer: Surgical Treatment Results and Prognostic Factors [dissertation]. São Paulo: "Faculdade de Medicina, Universidade de São Paulo"; 2009. 86p.

Locally advanced colorectal tumors are characterized by adherence or invasion of the primary tumor into surrounding structures and organs. For these patients, an en-bloc multivisceral resection represents the best alternative for cure. The aims of this study were to estimate the incidence of locally advanced lesions in our service, to evaluate operative results and to investigate factors that could influence prognosis. A retrospective cohort study was performed including 679 patients with colorectal cancer (CRC) who underwent surgery from 1995 to 2007. Clinical (age, gender, comorbidities), surgical and histological (tumor location, involved organs and tumor spreading) data were collected from patients with locally advanced colorectal cancer. Survival rates were estimated by the Kaplan-Meier curve considering only patients who underwent curative procedures. Ninety patients (13.2\%) with locally advanced tumors were identified. Average age was 59 years and there was a female predominance (61\%). Regarding topographic distribution, $66 \%$ of the lesions were colonic and $34 \%$ were located in the rectum. Gender distribution showed a higher prevalence of rectal tumors among women $(77 \% ; p=0.02)$. Postoperative morbidity occurred in $25.6 \%$ of the patients, the most common being abdominal wall infection (22\%), prolonged ileus $(14.8 \%)$ and anastomosis dehiscence $(11.1 \%)$. Mortality rate was $3.3 \%$. Involvement of adjacent organs was more frequently detected with the small intestine (19.9\%), bladder $(16.4 \%)$ and uterus $(12.9 \%)$. Concerning tumor penetration, there were detected T4 lesions in 58\% and T3 lesions in 42\%; Five years survival was smaller in the former lesions (50\% vs. $75 \%$; $p=0.01)$. During surgery 21.6 lymph nodes were resected on average, and the presence of positive nodes determined shorter survival $(35 \%$ vs. $80 \%, p=0.004)$. It was also observed shorter survival rates associated with other factors such as the presence of vascular, lymphatic, and perineural invasion (35\% vs. $80 \%, \mathrm{p}=0.02)$ and rectal tumor location compared to colonic ones ( $45 \%$ vs. $65 \%, p=0.01)$. On the other hand, the neoplastic (59\%) or inflammatory nature $(41 \%)$ of adhesions did not significantly influence survival rates $(55 \%$ vs. $65 \%, p=0.60)$. During the period of study it was possible to conclude that 1) locally advanced lesions represented $13.2 \%$ of the patients; 2 ) there were operative complications in $25 \%$ of the procedures; 3 ) survival of patients undergoing curative-intended surgery had a negative impact with deeper tumor wall penetration, vascular, lymphatic and/or perineural invasion, rectal location (compared to colonic) 
and positive lymph nodes. 4) other variables such as histological type, tumoral differentiation and number of resected organs, blood transfusion and character of adhesions between organs did not affect chances of survival.

Descriptors: colorectal cancer, prognosis, disease progression, survival analysis. 


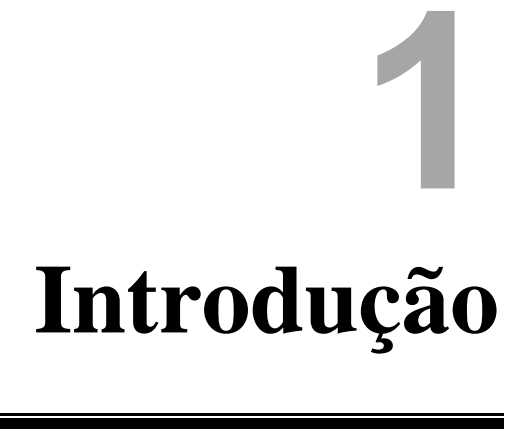




\subsection{Importância do assunto}

O Câncer Colorretal (CCR) constitui hoje uma neoplasia de ocorrência universal e importância crescente como problema de saúde pública. Sua incidência varia de maneira importante entre os diferentes países, representando a terceira causa de câncer no mundo em ambos os sexos e a segunda em países desenvolvidos, com especial destaque para a América do Norte, Europa Setentrional e Nova Zelândia. Embora os padrões geográficos sejam similares entre homens e mulheres, o câncer de reto é cerca de $20 \%$ a $50 \%$ mais freqüente em homens na maioria das populações ${ }^{2}$. Nos Estados Unidos, o CCR representa o segundo tumor maligno mais comum, tanto em homens como em mulheres, com uma estimativa anual de 145.000 novos casos, a maioria deles (72\%) localizados no cólon ${ }^{3,4}$.

Com exclusão dos tumores de pele não melanoma, o CCR é o $4^{\circ}$ câncer mais freqüente em homens (ficando atrás dos tumores da próstata, traquéia/brônquios/pulmão e estômago) e o $3^{\circ}$ em mulheres (mama e colo de útero), segundo dados atuais do Instituto Nacional do Câncer. No Brasil, estima-se que foram diagnosticados 12.490 e 14.500 casos novos em homens e mulheres, respectivamente, durante o ano de $2008^{2}$. 
Fatores de risco hereditários e ambientais (dietéticos ou não) estão envolvidos no desenvolvimento do CCR. As alterações genéticas que levam ao CCR podem ser adquiridas, gerando o chamado câncer esporádico que é responsável por $75 \%$ a $85 \%$ dos casos. Nesses casos existe uma ação cumulativa de agentes carcinógenos ambientais e dietéticos sobre a mucosa intestinal, levando a modificações específicas no ácido desoxirribonucléico $(A D N)$ das células do epitélio intestinal ${ }^{5}$.

Em outras circunstâncias, o indivíduo já apresenta ao nascimento ou adquire precocemente mutações específicas que desencadeiam as formas hereditárias do CCR, representadas principalmente pela polipose adenomatosa familiar (PAF) e pelo câncer colorretal hereditário não associado à polipose (mais conhecido pela sigla em inglês HNPCC) ${ }^{6,7}$.

Quanto à influência da alimentação, é sabido que a dieta ocidental caracterizada por alto teor de gordura saturada, juntamente com a ingestão excessiva de proteína de origem animal (carne vermelha, carne processada) e baixo teor de fibras (frutas, vegetais e cereais) está associada à maior potencial carcinogênico ${ }^{5}$. Também são considerados nocivos os fatores relacionados ao estilo de vida como fumo, sedentarismo, obesidade, consumo excessivo de álcool e ingestão de aminas heterocíclicas e hidrocarbonetos aromáticos ${ }^{8}$. Como fatores protetores são citados o cálcio, a vitamina $D$, os folatos, o selênio e os antioxidantes ${ }^{9}$.

A disseminação do CCR pode ocorrer por via linfática, hematogênica, por contigüidade, por via neural e por implantes ${ }^{10}$. Por via hematogênica, as 
células tumorais podem atingir o fígado, pulmões e ossos. Pela via linfática, a invasão se dá através dos gânglios epicólicos, pericólicos, intermediários e principais. Por contigüidade, os tumores invadem órgãos adjacentes, pela proximidade.

Atualmente considera-se que o estadiamento do CCR no momento do diagnóstico seja o fator prognóstico mais importante $3,6,11,12$. 0 estadiamento pré, intra e pós-operatório permite fazer uma estimativa da disseminação neoplásica tanto local como à distância. Seus objetivos são: a) definir a conduta terapêutica; b) estimar o prognóstico; c) avaliar a necessidade de tratamento complementar; d) e, no seguimento pósoperatório, fazer o diagnóstico de recidivas. Os exames mais utilizados, nessa etapa, são a ultrassonografia, a tomografia computadorizada, o ultrassom endorretal, a ressonância magnética e a tomografia por emissão de pósitrons (PET-SCAN) ${ }^{6}$. Da mesma forma, a realização do exame endoscópico do cólon no pré-operatório auxilia na identificação da lesão primária e também de tumores sincrônicos, fato que pode influir na estratégia operatória. Quando este exame não é possível, essas informações podem ser obtidas com menor acurácia pelo enema de duplo contraste, devendo-se postergar a colonoscopia para o seguimento pósoperatório $^{13,14}$.

Do ponto de vista oncológico, o tratamento cirúrgico radical do CCR exige o cumprimento de alguns preceitos técnicos, como a ligadura dos vasos principais em sua origem para exérese dos linfonodos que drenam a região que contém o tumor, a obtenção do segmento extirpado com margens livres 
da lesão, mínima manipulação da massa tumoral para evitar a disseminação das células neoplásicas, exérese das metástases quando possível e a ressecção alargada (em monobloco) dos órgãos e das estruturas vizinhas aderidas, eventualmente comprometidas pelo câncer invasivo.

Quando a neoplasia intestinal atravessa a serosa do órgão e invade ou adere em outras vísceras ou estruturas vizinhas, caracteriza-se um tumor localmente avançado (classificação T4 da União Internacional Contra o Câncer - UICC). Nesses casos, o tratamento adequado requer uma ressecção ampla que envolva o tumor primário e todos os tecidos e órgãos comprometidos em monobloco, sempre que tecnicamente factível ${ }^{11}$. Esta é a única medida que possibilita a cura, pois o emprego isolado de tratamento adjuvante pela quimioterapia e radioterapia não possibilita o controle total desse estágio da doença ${ }^{15,16,17,18}$.

Apesar de todo arsenal tecnológico atualmente disponível para se fazer o estadiamento no pré-operatório, algumas vezes a extensão do comprometimento tumoral só é conhecida no ato operatório, durante a inspeção da cavidade abdominal ${ }^{19,20}$. Assim, ao se verificar invasão local por contigüidade, o conhecimento da anatomia topográfica da cavidade abdominal assume importância capital para o cirurgião que se depara com esta situação clínica. O cólon tem relação anatômica com todas as vísceras abdominais e com a parede abdominal; da mesma forma, o reto mantém relação com os órgãos e estruturas urológicas e ginecológicas, além do arcabouço pélvico ${ }^{4,19,21,22 .}$ 
Reconhece-se que neste estágio evolutivo da doença o tratamento cirúrgico determina maior morbi-mortalidade; além disso, a presença de comprometimento ganglionar local está associada com menores índices de sobrevida $23,24,25,26$.

$\mathrm{Na}$ avaliação intra-operatória de outros órgãos e/ou estruturas aderidas é importante ressaltar que essas aderências podem ser inflamatórias ou neoplásicas, diferenciação que nem sempre é possível obter antecipadamente ou no ato operatório. Assim, não se recomenda fazer biópsias ou separar essas estruturas, a fim de não disseminar células neoplásicas ${ }^{421}$. Corre-se ainda o risco de, ao fazê-lo, desencadear a perfuração da víscera com conseqüente contaminação da cavidade abdominal. Além disso, em número expressivo de vezes, a biópsia é inconclusiva e a confirmação do comprometimento neoplásico ou inflamatório só será obtida posteriormente pelo exame histológico da peça ressecada $27,28,29,30,31,32,33,34$.

$\mathrm{Na}$ literatura, a incidência de CCR localmente avançado varia consideravelmente, tendo sido registrado cifras de $5 \%$ a $22 \%$ dos carcinomas colorretais 16,18, 21, 25, 35, 36. Há cerca de 60 anos, um tumor com essas características era considerado inoperável e a doença incurável. Entretanto, os avanços técnicos e anestésicos ao longo das décadas tornaram possível realizar operações cada vez mais complexas e com intenção curativa ${ }^{37}$.

O primeiro autor a citar a cirurgia multivisceral para o CCR localmente avançado foi Moynihan, em $192{ }^{38}$. Mais tarde, em 1946, Sugarbaker publicou série com um número considerável de pacientes que foram 
acompanhados por longo período, relatando os benefícios do tratamento operatório quanto à sobrevida, apesar da morbidade ${ }^{39}$. Desde então, diversas publicações se dedicaram a pesquisar e divulgar os resultados do tratamento de doentes com essas características.

\subsection{Objetivos}

Tendo em mente os dados aqui apresentados, foram objetivos do presente estudo:

a) estimar a incidência de câncer colorretal localmente avançado em nosso meio; (entre todos os pacientes operados por câncer colorretal no Hospital das Clínicas da Faculdade de Medicina da Universidade de São Paulo, no período de $1^{\circ}$ de julho de 1995 a 30 de junho de 2007, os quais tinham a forma localmente avançada e foram submetidos à ressecção multivisceral);

b) avaliar os índices de morbi-mortalidade associados com as intervenções alargadas;

c) analisar os benefícios das ressecções multiviscerais em termos de sobrevida, considerando a influência de variáveis clínicas, patológicas e operatórias. 


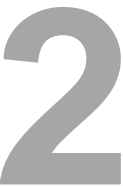

Métodos 


\subsection{Caracterização da casuística}

O projeto de pesquisa prévio foi submetido à apreciação e aprovado pela Comissão de Ética do Hospital das Clínicas da Faculdade de Medicina da Universidade de São Paulo (SP).

Realizou-se um estudo coorte retrospectivo pela análise de prontuários de 679 pacientes com diagnóstico de câncer colorretal que foram internados no Serviço de Cirurgia do Cólon, Reto e Ânus do Hospital das Clínicas (Departamento de Gastroenterologia, Disciplina de Coloproctologia da Faculdade de Medicina da Universidade de São Paulo) no período de $1^{\circ}$ de julho de 1995 a 30 de junho de 2007.

Dentre esses pacientes foram separados para análise somente os que foram submetidos a ressecções multiviscerais devido a tumores primários localmente invasivos. 


\subsection{Levantamento de dados}

Foram coletados dados dos prontuários referentes às características clínicas dos pacientes (idade, sexo, co-morbidades) e ao tumor primário (localização da neoplasia, relação dos órgãos invadidos por contigüidade, presença de disseminação tumoral, ascite ou metástases). Esses dados foram obtidos através de exames como colonoscopia, exames de imagem (raios-x simples de tórax, ultrassonografia, tomografia computadorizada), descrição do ato operatório e exames histológicos.

A obtenção do número de pacientes submetidos à ressecção alargada nos últimos doze anos permitiu obter a incidência dessa ocorrência em nosso meio, assim como a freqüência de invasão neoplásica confirmada pelo exame anatomopatológico da peça.

Foram consideradas cirurgias de caráter paliativo aquelas em que se observou a presença de tumor residual macroscópico (também denominadas ressecção R2), as com presença de margens positivas para neoplasia à microscopia (ou ressecção R1) ou ainda doença sistêmica ou localizada em outro local da cavidade abdominal. A ausência desses elementos caracterizou a intenção curativa da ressecção (R0).

O exame histológico da peça cirúrgica retirada permitiu a confirmação do diagnóstico primário, das características tumorais (tipo histológico grau de diferenciação, presença de invasão perineural e/ou embolização vascular e linfática e comprometimento linfonodal), além da natureza das aderências 
entre os órgãos. Os tumores foram estadiados segundo a classificação TNM e encontravam-se nos estadios T3 e T4, segundo a classificação TNM/AJCC ${ }^{39}$.

Anotaram-se também os dados clínicos e radiológicos obtidos no seguimento ambulatorial que levaram ao diagnóstico de recidiva tumoral. De acordo com a descrição do ato operatório e da evolução dos pacientes, tentamos estabelecer uma correlação das variáveis que potencialmente interferiram no prognóstico dos doentes, em termos de sobrevida global e livre da doença.

Do mesmo modo, registrou-se dados como a necessidade de transfusão sangüínea, a evolução no pós-operatório recente, incluindo a ocorrência de morbi-mortalidade pós-operatória. Foram discriminados os óbitos e complicações que ocorreram durante a internação (ou até 30 dias decorridos da data do procedimento cirúrgico) daqueles que ocorreram tardiamente por outras causas.

A análise da sobrevida global em cinco anos foi documentada a partir da data da cirurgia até o período final de seguimento (dia 30 de junho de 2007) pelas anotações preenchidas nos prontuários.

Os pacientes considerados perdidos foram os que não retornaram nas datas marcadas para retorno e não foram encontrados após várias tentativas de manter contato por via telefônica ou pelo serviço social do hospital.

Optou-se por excluir oito pacientes que, embora tivessem sido tratados por cirurgia alargada devido à presença de outros órgãos e/ou estruturas aderidas, eram portadores de tumores pT2 ao exame histológico, 
ou seja, não ultrapassavam a camada muscular própria da parede intestinal e portanto as aderências eram só inflamatórias, não caracterizando um tumor localmente avançado.

De posse desses dados, confrontaram-se as anotações ambulatoriais de seguimento e sobrevida com os fatores que pudessem interferir no prognóstico.

\subsection{Análise estatística}

Realizou-se análise estatística descritiva para todas as variáveis, observando-se um intervalo de confiança de 95\% $(p<0,05)$.

Para as variáveis qualitativas como sexo e grau de diferenciação do tumor, foram calculadas freqüências e percentuais; para as quantitativas como idade, número de linfonodos comprometidos, tempo de cirurgia e tempo de sobrevida, foram usadas medidas-resumo (cálculo da média, da mediana e do desvio-padrão).

A fim de se confirmar a diferença existente entre a localização do tumor em relação ao sexo foi usado o teste do qui-quadrado $\left(x^{2}\right)$ e o teste exato de Fisher ${ }^{40}$. 
A análise da influência das variáveis no tempo de sobrevida foi realizada através do estimador de Kaplan-Meier ${ }^{41}$ da curva de sobrevivência.

A fim de verificar a influência das variáveis individualmente, estimouse a sobrevivência para cada categoria, através do teste de Logrank.

Para a análise de sobrevivência utilizou-se também uma extensão do modelo de riscos proporcionais de Cox ${ }^{42}$ proposta por Tsodikov ${ }^{43,44}$, escolhido por haver frações de cura (não foram todos os pacientes que tiveram o desfecho morte).

Para representar a distribuição de um conjunto de dados com base em alguns de seus parâmetros descritivos, como a mediana, o quartil inferior, o quartil superior e do intervalo interquartil foi utilizado o gráfico BOXPLOT. Ele permite avaliar a simetria dos dados, sua dispersão e a existência ou não de outliers (pontos atípicos) nos mesmos, sendo especialmente adequado para a comparação de dois ou mais conjuntos de dados correspondentes às categorias de uma variável qualitativa. 


\section{Resultados}


Neste capítulo são apresentados os resultados obtidos em cada uma das variáveis estudadas. Na parte final, apresentamos uma tabela que contém um resumo dos fatores em que se encontrou diferença estatística significante quanto à sobrevida de cinco anos, considerando $p<0,05$.

\subsection{Sexo, idade e localização do tumor primário}

Dentre os 679 pacientes com diagnóstico de câncer colorretal que foram internados no período entre 1995 e 2007, 90 apresentavam a doença localmente avançada e foram tratados por ressecção alargada, o que configura uma incidência de 13,2\% para essa condição.

A idade média dos pacientes foi de 59,5 anos (mediana=61), sendo que o indivíduo mais jovem tinha 24 anos e o mais idoso 88, como se observa na Tabela 1.

Tabela 1: Média de idade e variações

\begin{tabular}{cccccc}
\hline Variável & Mínima & Mediana & Máxima & Média & Desvio padrão \\
\hline Idade & 24 & 61 & 88 & 59,5 & 15,5 \\
\hline
\end{tabular}


Cinqüenta e cinco pacientes eram do sexo feminino $(61,1 \%)$ e 35 do masculino $(38,9 \%)$. Trinta e um tumores estavam primariamente localizados no reto $(34,5 \%)$ e 59 distribuídos nos diversos segmentos do cólon $(65,5 \%)$. Entre os tumores retais observou-se um predomínio entre as mulheres (24; 77,7\%) em comparação aos homens (7; 22,3\%). Já a distribuição dos tumores colônicos foi semelhante em ambos os sexos (mulheres $31 ; 52,5 \%$ e homens $28 ; 47,5 \%$ ) (Tabela 2 e Figura 1).

Tabela 2: Sexo e localização dos tumores

\begin{tabular}{lcccc}
\hline & Cólon & $\%$ & Reto & $\%$ \\
\hline Feminino & 31 & 52,5 & 24 & 77,4 \\
Masculino & 28 & 47,5 & 7 & 22,6 \\
\hline Total & $\mathbf{5 9}$ & $\mathbf{1 0 0}$ & $\mathbf{3 1}$ & $\mathbf{1 0 0}$ \\
\hline
\end{tabular}



Figura 1: Distribuição da localização dos tumores em relação ao sexo 
Na Tabela 3 está apresentada a distribuição dos tumores colônicos e retais, onde se nota que a frequência tende a ser maior no sexo feminino na maioria dos segmentos (com exceção do cólon transverso). Este fato pode reforçar a relação entre diferentes padrões de freqüência entre o sexo e o local do tumor.

Tabela 3: Sexo e locais do tumor primário

\begin{tabular}{lcccccc}
\hline \multicolumn{7}{c}{ Sexo } \\
\hline Local do tumor & Feminino & \% & Masculino & $\%$ & Total & $\%$ \\
\hline Reto & 24 & 26,7 & 7 & 7,8 & 31 & 34,5 \\
Sigmóide & 13 & 14,4 & 14 & 15,6 & 27 & 30 \\
Descendente & 6 & 6,6 & 3 & 3,3 & 9 & 10 \\
Transverso & 4 & 4,4 & 6 & 6,6 & 10 & 11 \\
Ascendente & 8 & 8,9 & 5 & 5,6 & 13 & 14,5 \\
\hline Total & $\mathbf{5 5}$ & $\mathbf{6 1}$ & $\mathbf{3 5}$ & $\mathbf{3 9}$ & $\mathbf{9 0}$ & $\mathbf{1 0 0}$ \\
\hline
\end{tabular}

A análise estatística demonstrou que o tumor no reto foi mais freqüente em pacientes do sexo feminino, enquanto a freqüência do tumor primário nos vários segmentos colônicos foi semelhante em ambos os sexos $\left(p=0,02\right.$ para o teste $X^{2}$ e para o teste Exato de Fisher $\left.{ }^{40}\right)$; 


\subsection{Das operações realizadas}

O tempo operatório médio foi de 304,3 minutos, variando de 150 minutos (mínimo) a 590 minutos (máximo). A maior parte dos procedimentos foi realizada na faixa de 240 a 350 minutos.

Foram realizadas $76(84,4 \%)$ operações com intenção curativa (R0, sem tumor residual), sendo consideradas paliativas outras $14(15,6 \%)$, pois já apresentavam metástases no momento do diagnóstico e/ou do tratamento cirúrgico. As ressecções paliativas designadas R1 (tumor microscópico residual) ou R2 (tumor macroscópico residual) não foram incluídas no estudo da sobrevida.

A comparação das taxas de sobrevida dos pacientes nessas condições mostrou que nenhum daqueles tratados em caráter paliativo atingiu cinco anos de sobrevida no seguimento pós-operatório. Entretanto, as operações consideradas curativas proporcionaram sobrevida de cinco anos em $60 \%$ dos doentes $(p=0,001)$.

Os procedimentos cirúrgicos realizados foram classificados como principais (que se destinaram ao tratamento do tumor primário) ou secundários (realizados para extirpar em monobloco os órgãos e/ou estruturas aderidas à tumoração primária do cólon ou reto).

Os procedimentos principais estão relacionados na Tabela 4. Foram realizadas $39(43,3 \%)$ retossigmoidectomias, $17(18,9 \%)$ colectomias direitas, $15(16,7 \%)$ amputações abdominoperineais do reto, oito $(8,9 \%)$ 
colectomias esquerdas, seis $(6,7 \%)$ colectomias totais, três $(3,3 \%)$ ressecções parciais do cólon transverso, um $(1,1 \%)$ colectomia subtotal e uma $(1,1 \%)$ exenteração pélvica.

Tabela 4: Procedimentos cirúrgicos principais

\begin{tabular}{lcc}
\hline Procedimentos & Freqüência (n) & $\%$ \\
\hline Retossigmoidectomia & 39 & 43,3 \\
Colectomia direita & 17 & 18,9 \\
Amputação abdominoperineal do reto & 15 & 16,7 \\
Colectomia esquerda & 8 & 8,9 \\
Colectomia total & 6 & 6,7 \\
Ressecção parcial do cólon transverso & 3 & 3,3 \\
Colectomia subtotal & 1 & 1,1 \\
Exenteração pélvica & 1 & 1,1 \\
\hline Total & $\mathbf{9 0}$ & $\mathbf{1 0 0}$ \\
\hline
\end{tabular}

Dentre os 31 pacientes (34,5\%) com câncer no reto, a neoplasia foi diagnosticada no reto distal em $17(18,9 \%)$, tendo sido tratados por quimioterapia e radioterapia pré-operatórias conforme protocolo adotado no departamento ${ }^{45}$. Nessa localização, $15(16,7 \%)$ tumores foram tratados por amputação abdominoperineal, 15 (16,7\%) por ressecção anterior baixa e em um $(1,1 \%)$ foi necessária a exenteração pélvica.

Os órgãos e/ou estruturas aderidas que foram ressecados em monobloco com o segmento que continha o tumor primário estão relacionados na Tabela 5 . 
O mais freqüentemente atingido foi o intestino delgado, em 23 pacientes $(19,8 \%)$. Constatou-se ainda o envolvimento de outros órgãos como a bexiga em $19(16,4 \%)$, o útero em $15(12,9 \%)$, os ovários e as trompas em $13(11,2 \%)$, a vagina em $11(9,5 \%)$, parte de parede abdominal em seis $(5,2 \%)$, o baço em cinco $(4,3 \%)$, outro segmento do cólon e ureter em quatro $(3,5 \%$ cada); o estômago a vesícula biliar e uma massa retroperitonial que compreendia o tecido tumoral, o peritônio parietal posterior com os linfonodos adjacentes mais os vasos e tecido fibroso apareceram em três procedimentos $(2,6 \%)$; parte do fígado em dois $(1,8 \%)$ e rim, vulva, pâncreas, parte do diafragma, vesícula seminal com o ducto deferente em um paciente cada $(0,8 \%)$. O número de órgãos acometidos variou, tendo pacientes com um ou mais órgãos comprometidos.

Tabela 5: Freqüência dos órgãos ressecados em bloco

\begin{tabular}{lcc}
\hline Órgãos ressecados em bloco & Freqüência & $\%$ \\
\hline Intestino delgado & 23 & 19,8 \\
Bexiga & 19 & 16,4 \\
Útero & 15 & 12,9 \\
Ovário e trompa & 13 & 11,2 \\
Vagina & 11 & 9,5 \\
Parede abdominal & 6 & 5,2 \\
Baço & 5 & 4,3 \\
Outro segmento do cólon e ureter & 4 & 3,5 \\
Estômago, vesícula e massa retro-peritonial & 3 & 2,6 \\
Parte do fígado & 2 & 1,8 \\
Rim, vulva, pâncreas, parte do diafragma, & 1 & 0,8 \\
Vesícula seminal e ducto deferente & & $\mathbf{1 0 0}$ \\
\hline Total & 116 & \\
\hline
\end{tabular}


A seguir, nas Figuras de números 2 a 8 pode-se avaliar alguns tipos de comprometimento citados anteriormente.



Figura 2: Colectomia total + enterectomia segmentar + colecistectomia

Tumor primário no ângulo hepático do cólon, com invasão de alça de delgado e da vesícula biliar, que também continha cálculos. Retirada também do restante do cólon devido a presença de pólipos esparsos. 


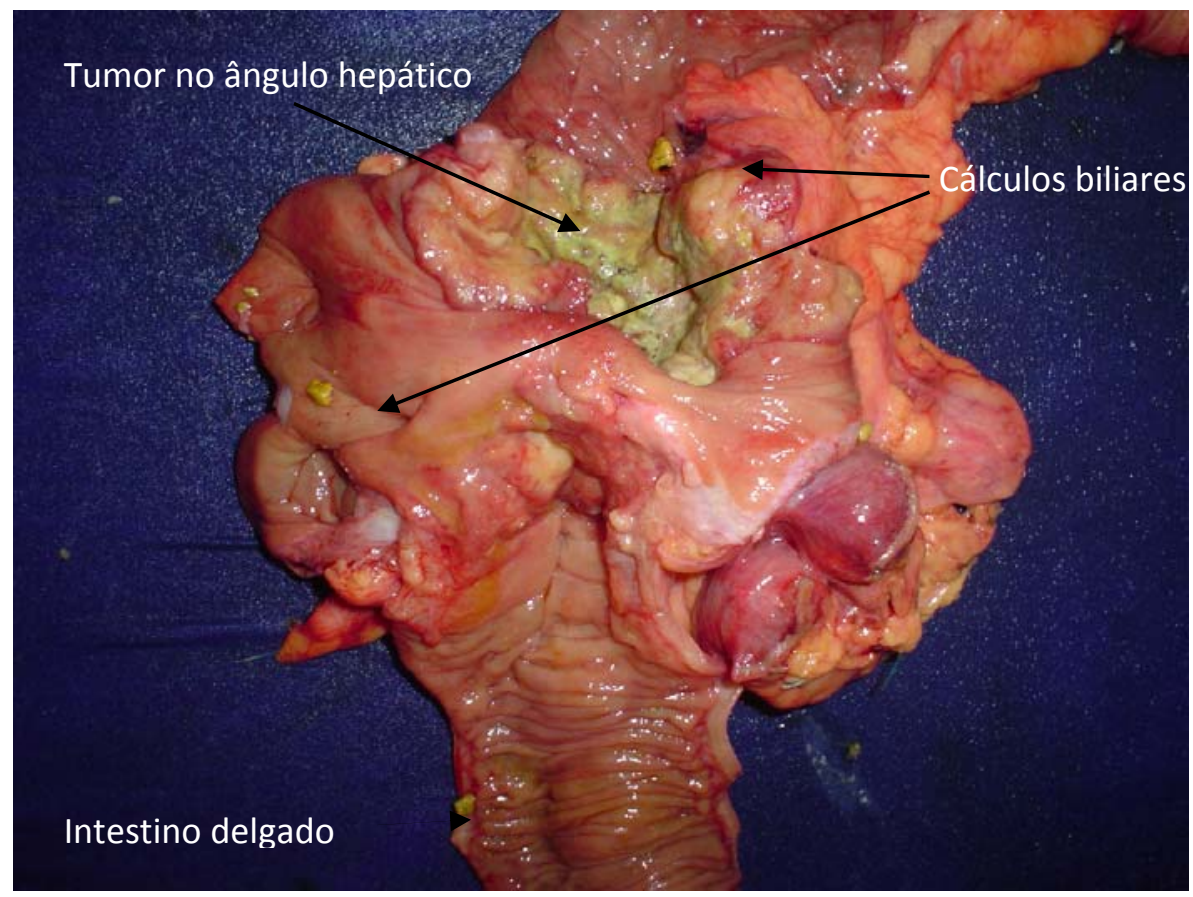

Figura 3: Localização do tumor primário no ângulo hepático

As figuras a seguir mostram o tumor de reto invasivo.

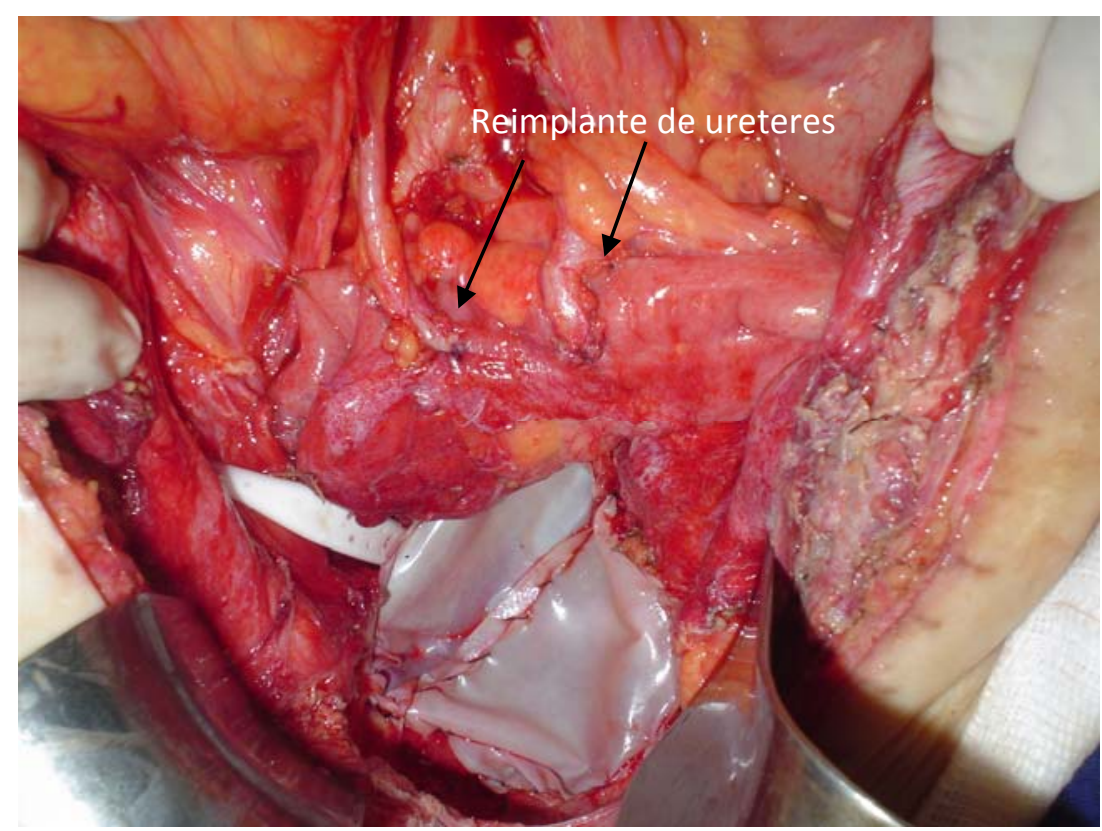

Figura 4: Amputação abdominoperineal do reto com cistectomia total e reimplante ureteral (neoplasia do reto com invasão da bexiga) 


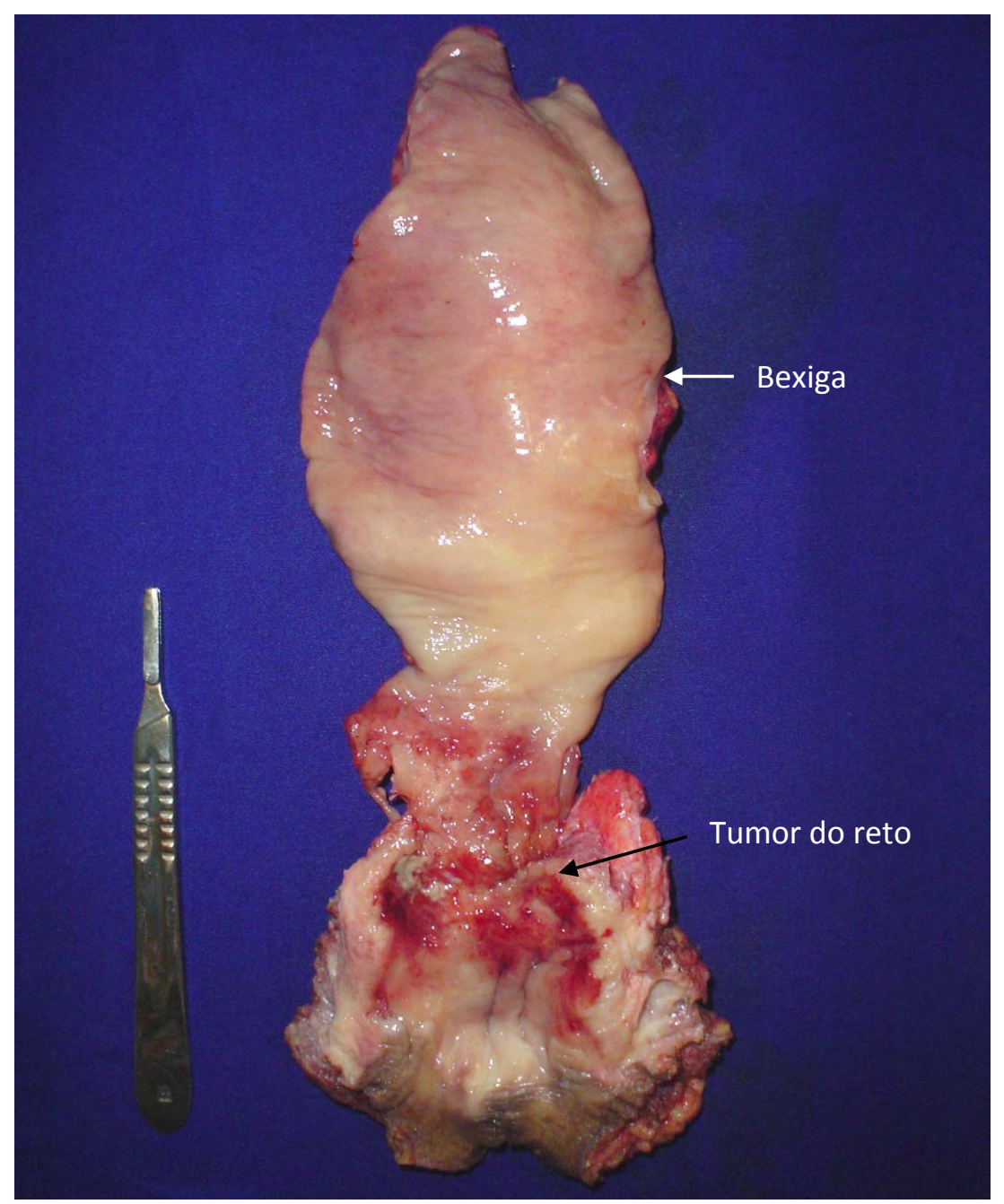

Figura 5: Amputação abdominoperineal do reto e cistectomia total

Essa figura mostrou um tumor de reto invadindo a bexiga.

As Figuras 6 e 7 mostram o comprometimento da parede abdominal lateral esquerda, por um tumor avançado de sigmóide. 


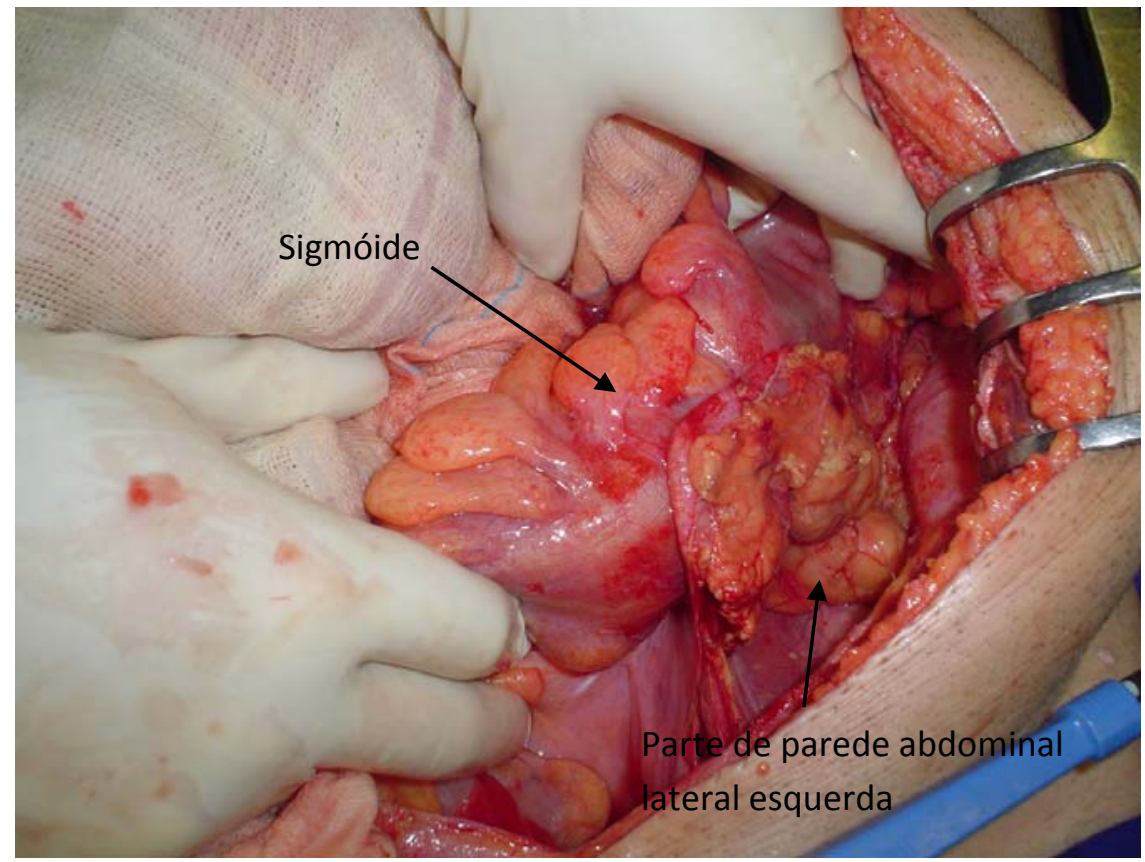

Figura 6: Ressecção de parte da parede lateral esquerda do abdome

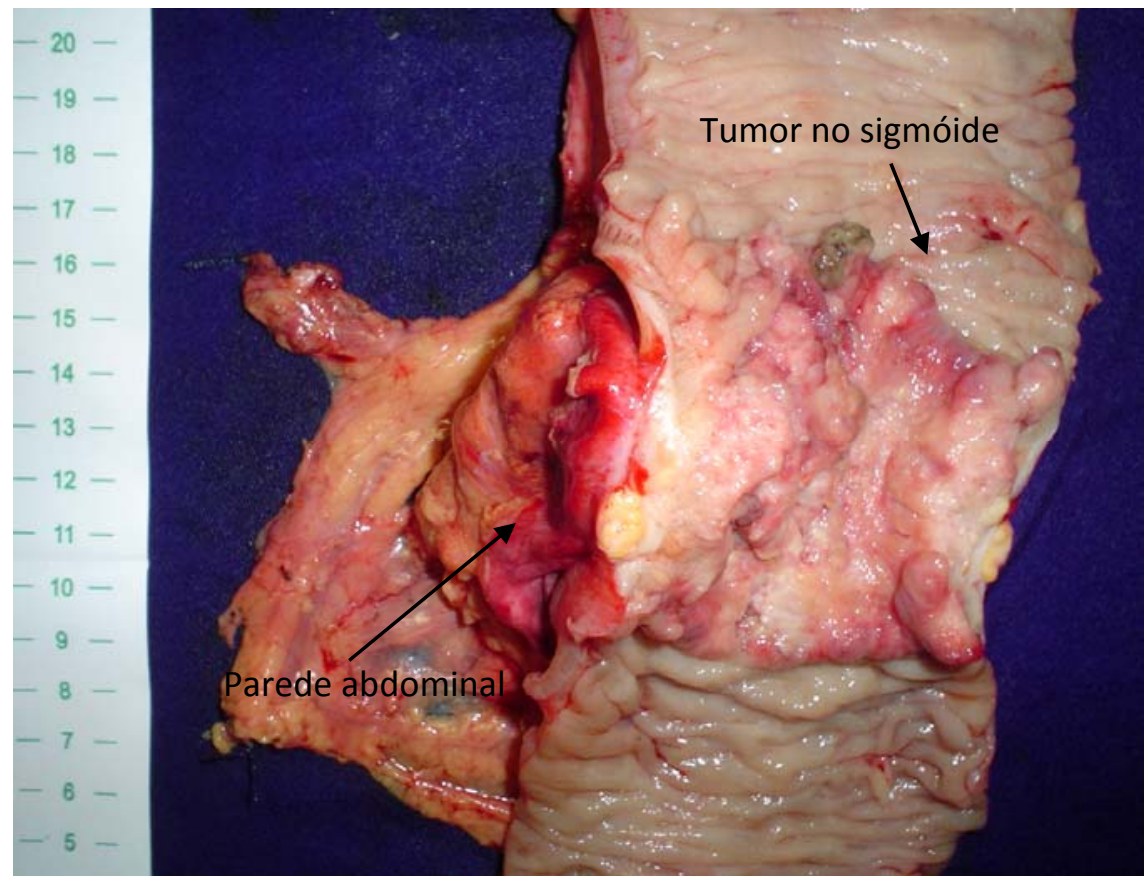

Figura 7: Sigmóide + parte da parede lateral esquerda do abdome 
Na Figura 8 temos o resultado de um exame de imagem, no caso uma tomografia computadorizada da pelve, que permite avaliar no pré-operatório, a invasão do tumor do reto em direção à bexiga.

\section{Tumor do reto invadindo a bexiga}

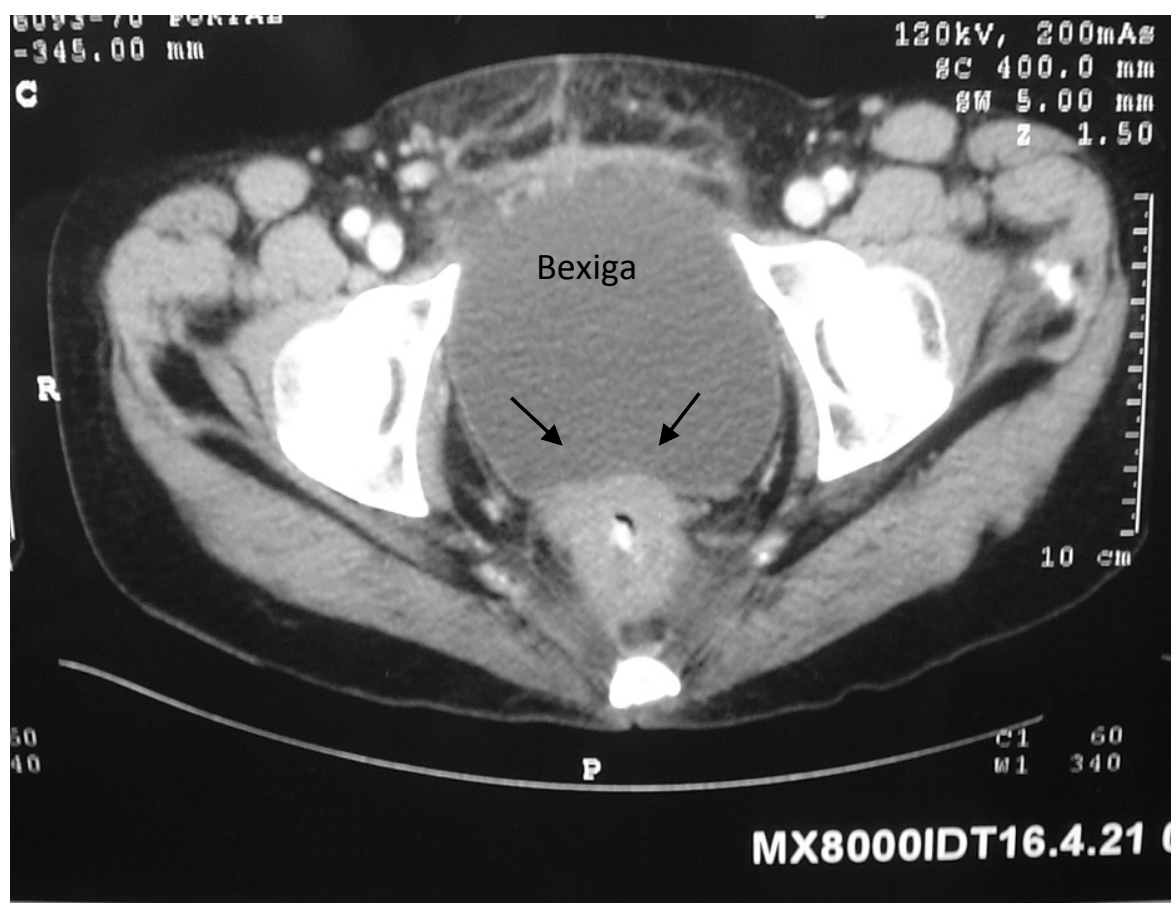

Figura 8: Tomografia computadorizada da pelve mostrando invasão da bexiga por um tumor primário do reto

No tratamento cirúrgico houve necessidade de colostomia em 17 doentes $(18,9 \%)$, incluindo os $15(16,7 \%)$ que sofreram amputação abdominoperineal do reto e seis ileostomias $(6,7 \%)$, nos doentes que foram submetidos à colectomia total. 
Cinqüenta e sete por cento dos operados tiveram apenas um órgão ressecado aderido ao tumor primário, $29 \%$ possuíam dois órgãos aderidos e $14 \%$ apresentaram três ou mais órgãos envolvidos na massa tumoral (Figura 9).

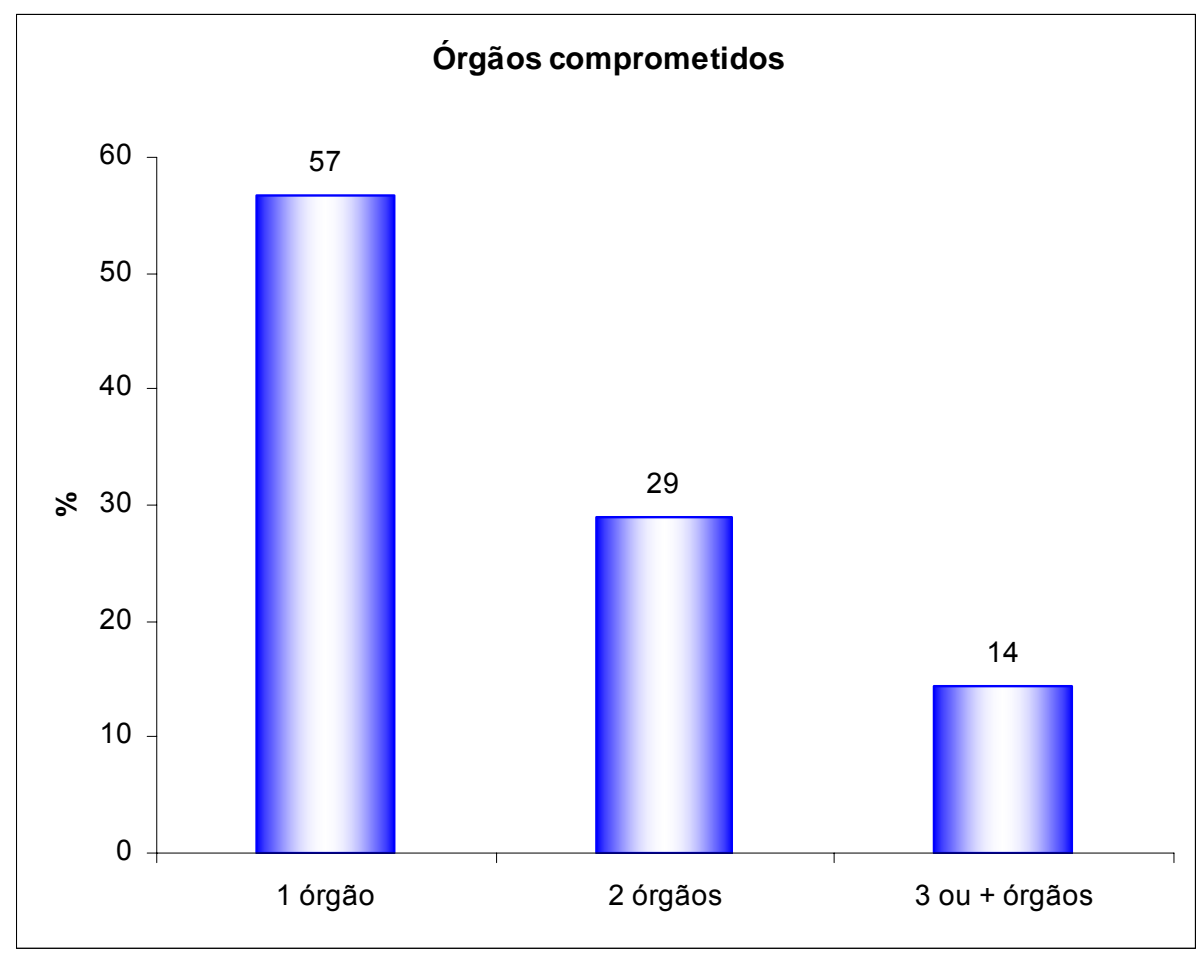

Figura 9: Porcentagem de órgãos ressecados em monobloco, aderidos ao tumor primário

Houve necessidade de realizar transfusão sangüínea em 41 pacientes $(45,6 \%)$ em algum momento da internação e $49(54,4 \%)$ não necessitaram de transfusão. Para esses dados foi realizado o teste de Logrank e não houve diferença estatística significante, com $p=0,12$. Dentre os que necessitaram receber sangue, $19 \%$ receberam uma unidade, $44 \%$ 
receberam duas e $37 \%$ receberam três ou mais unidades, como está demonstrado na Figura 10. Foi realizado o mesmo teste para comparar a quantidade de unidades de sangue transfundidas, se uma, duas, três ou mais unidades e, também, não foi significativamente diferente, com $p=0,26$.

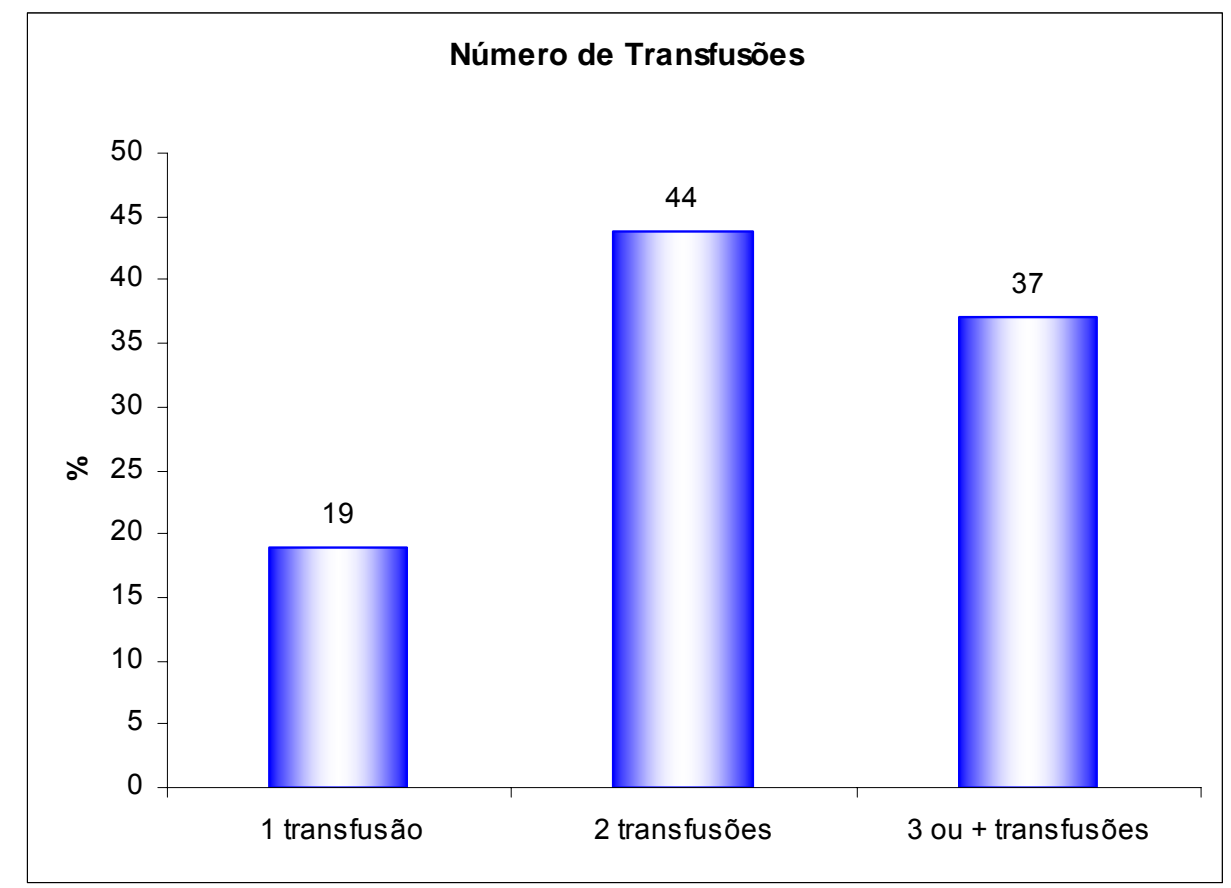

Figura 10: Distribuição da porcentagem dos pacientes que foram transfundidos

A análise da variável transfusão de sangue com o sexo dos pacientes mostra que $73 \%$ dos pacientes que foram transfundidos eram do sexo feminino e $27 \%$ do masculino (Figura 11). Observou-se diferença estatística pelo teste $x^{2}(p=0,04)$. 


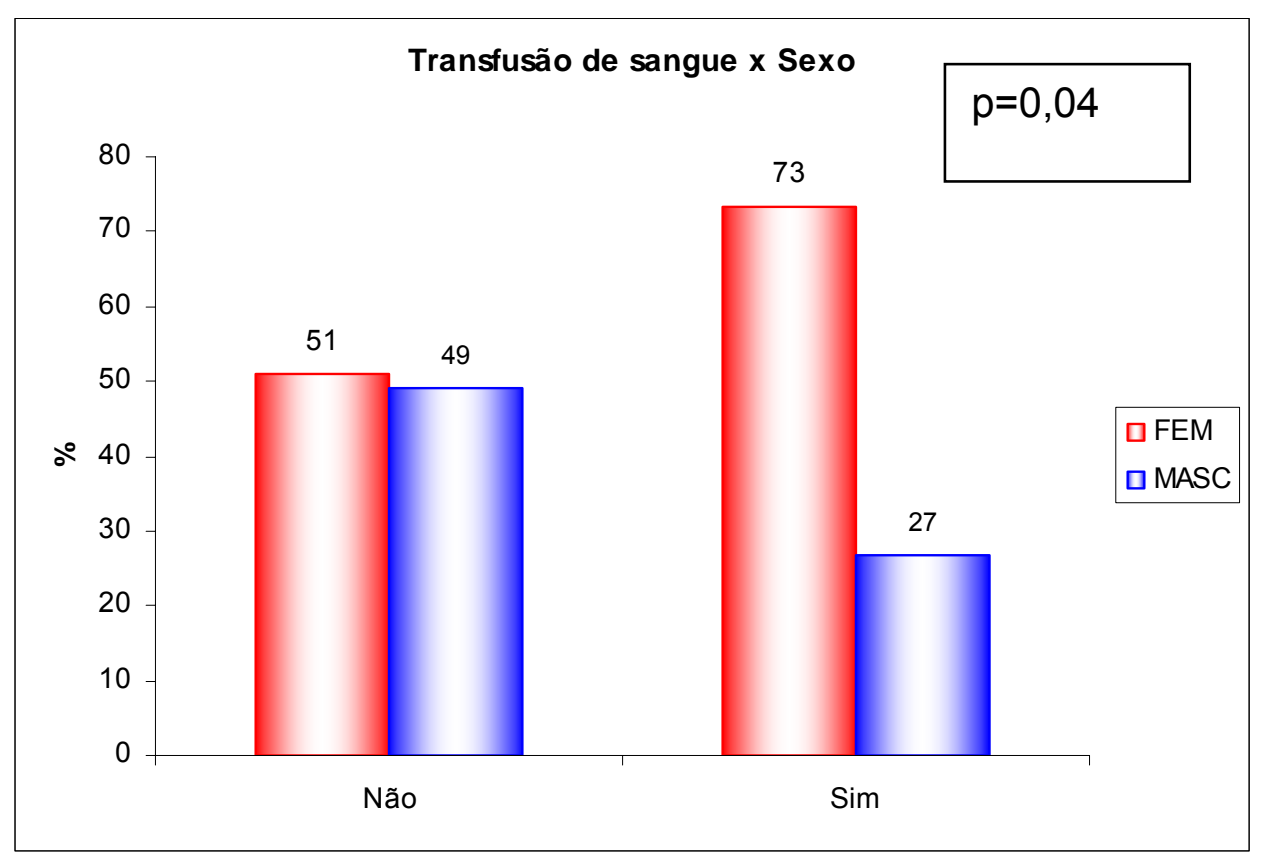

Figura 11: Distribuição da porcentagem de transfusão sangüínea em relação ao sexo

\subsection{Da morbi-mortalidade}

No pós-operatório, 23 dos 90 pacientes (25,6\%) apresentaram 27 intercorrências, sendo as mais comuns, deiscência e/ou infecção de parede, íleo prolongado e deiscência de anastomose $(22,2 \%, 14,9 \%$ e $11,1 \%$, respectivamente), que estão listadas na Tabela 6. 
Tabela 6: Causas de morbidade operatória

\begin{tabular}{lcc}
\hline Intercorrências & $\mathbf{N}^{\mathbf{0}}$ & $\%$ \\
\hline Deiscência/infecção de parede & 6 & 22,2 \\
Íleo prolongado & 4 & 14,9 \\
Deiscência de anastomose & 3 & 11,1 \\
Fístula urinária & 2 & 7,4 \\
Fístula vaginal & 1 & 3,7 \\
Fístula pancreática & 1 & 3,7 \\
Fístula biliar & 1 & 3,7 \\
Choque hemorrágico & 1 & 3,7 \\
Choque séptico & 1 & 3,7 \\
Suboclusão intestinal & 1 & 3,7 \\
Insuficiência renal aguda & 1 & 3,7 \\
Fibrilação atrial & 1 & 3,7 \\
Hematúria & 1 & 3,7 \\
Pneumotórax por cateter & 1 & 3,7 \\
Broncopneumonia & 1 & 3,7 \\
Drenagem de coleção pélvica & 1 & 3,7 \\
\hline Total & $\mathbf{2 7}$ & $\mathbf{1 0 0}$ \\
\hline
\end{tabular}

Dois pacientes necessitaram nova intervenção cirúrgica, um deles no décimo dia de pós-operatório devido a episódio de suboclusão intestinal, e outro para drenagem de abscesso pélvico após 14 dias da primeira operação.

Três pacientes $(3,3 \%)$ evoluíram a óbito até o $30^{\circ}$ dia de pós-operatório, sendo as causas representadas por choque hipovolêmico nas primeiras 24 horas $(1,1 \%)$, choque séptico devido deiscência de anastomose $(1,1 \%)$ e obstrução intestinal $(1,1 \%)$ no $28^{\circ}$ pós-operatório, sendo submetido à nova intervenção cirúrgica e evoluiu para septicemia e falência múltipla de órgãos. 
O período de internação médio foi de 21 dias, sendo o mínimo de três dias e o máximo de 63 dias.

Quanto ao seguimento ambulatorial, não foi possível obter dados de 10 pacientes $(11,1 \%)$, apesar da exaustiva busca de contato. Nesse período, ocorreram $25(27,8 \%)$ óbitos, sendo 23 (25,6\%) em decorrência de recidiva da doença. Outras causas foram insuficiência hepática, que ocorreu dois meses após a cirurgia em paciente portador de vírus da hepatite $C(1,1 \%)$ e outro por choque séptico $(1,1 \%)$.

A sobrevida global oscilou de 24,4 a 36,9 meses, com média de 30,6 meses. O tempo médio de sobrevida livre da doença foi de 29,7 meses, variando de 23 a 36,5 meses.

\subsection{Das características tumorais}

A seguir serão apresentados os resultados concernentes à penetração da neoplasia na parede intestinal, ao grau de diferenciação tumoral, ao comprometimento linfonodal e à invasão.

Foram realizadas oito cirurgias alargadas em pacientes em que o exame histopatológico da peça retirada revelou tratar-se de tumores T2. Esses foram excluídos do estudo desde o início, pois constituem lesão mais superficial. 
De acordo com a extensão em profundidade na parede do cólon e/ou reto, $38(42,2 \%)$ tumores encontravam-se no estadio T3 e $52(57,8 \%)$ no T4 (segundo a classificação TNM da UICC/AJCC ${ }^{39}$ ) com diferença estatística significante pelo teste de Logrank $(p=0,01)$.

Foi observado que $31(59,6 \%)$ pacientes com tumores T4 tinham localização no cólon e $21(40,4 \%)$ no reto, e que os números de linfonodos comprometidos nos grupos T3 e T4 foram similares, com $p=0,18$, não havendo diferença estatística significante entre os grupos, ao nível de significância de $5 \%$.

Quanto aos tipos histológicos, 68 (75,5\%) eram adenocarcinomas tubulares, $14(15,6 \%)$ eram do tipo epitelial (mucinoso e mucocelulares, células em anel de sinete) ${ }^{46}$ e oito $(8,9 \%)$ túbulos-vilosos (Figura 12). Não houve diferença estatística significante nesta distribuição ( $p=0,94$ no teste de Logrank).

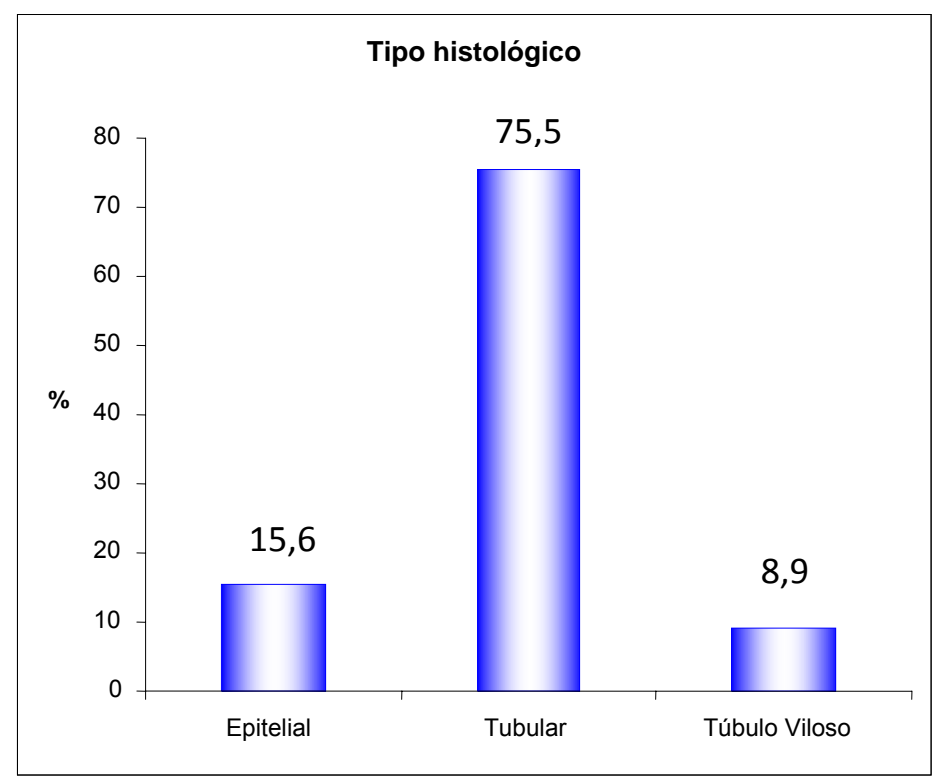

Figura 12: Distribuição da porcentagem do tipo histológico 
A grande maioria das neoplasias $74(82,2 \%)$ apresentava moderado grau de diferenciação. Em menor proporção, os tumores pouco e bem diferenciados foram encontrados em número de $8(8,9 \%)$ cada um. A distribuição dos graus de diferenciação tumoral em porcentagem aproximada está demonstrada na Figura 13.

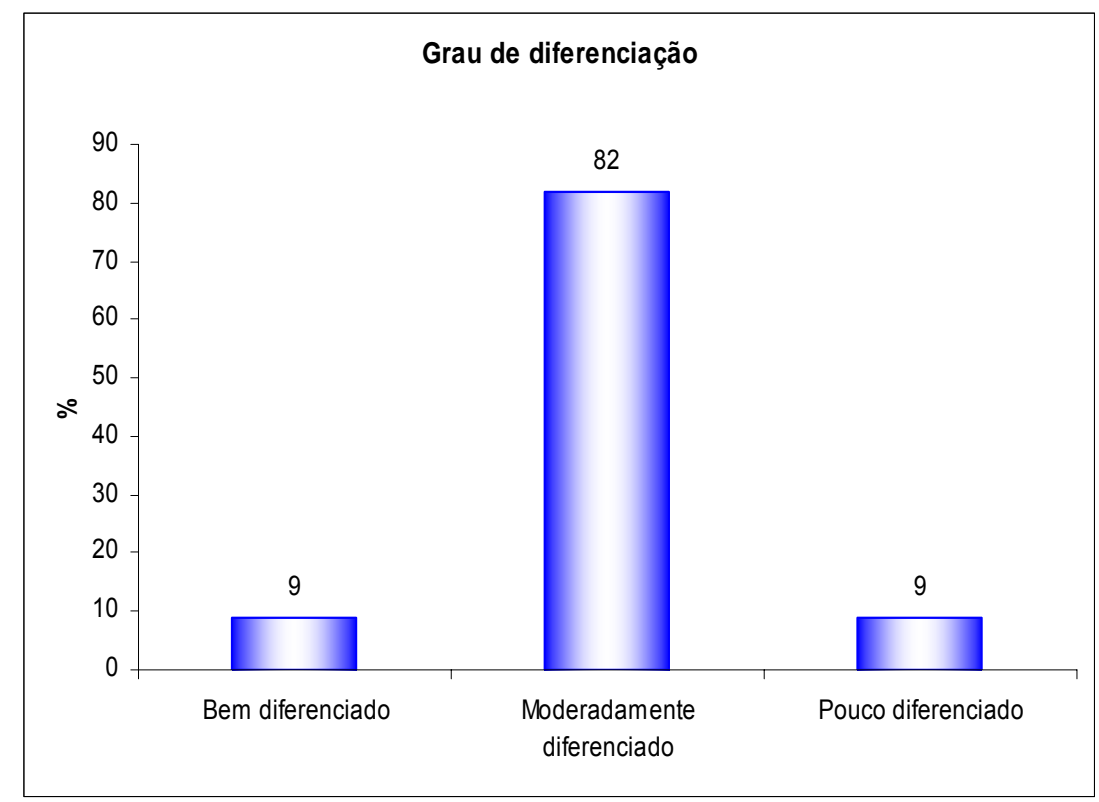

Figura 13: Grau de diferenciação

Quanto ao comprometimento ganglionar (Figura 14), não se constataram células neoplásicas em linfonodos provenientes de 38 pacientes $(42,2 \%)$. 


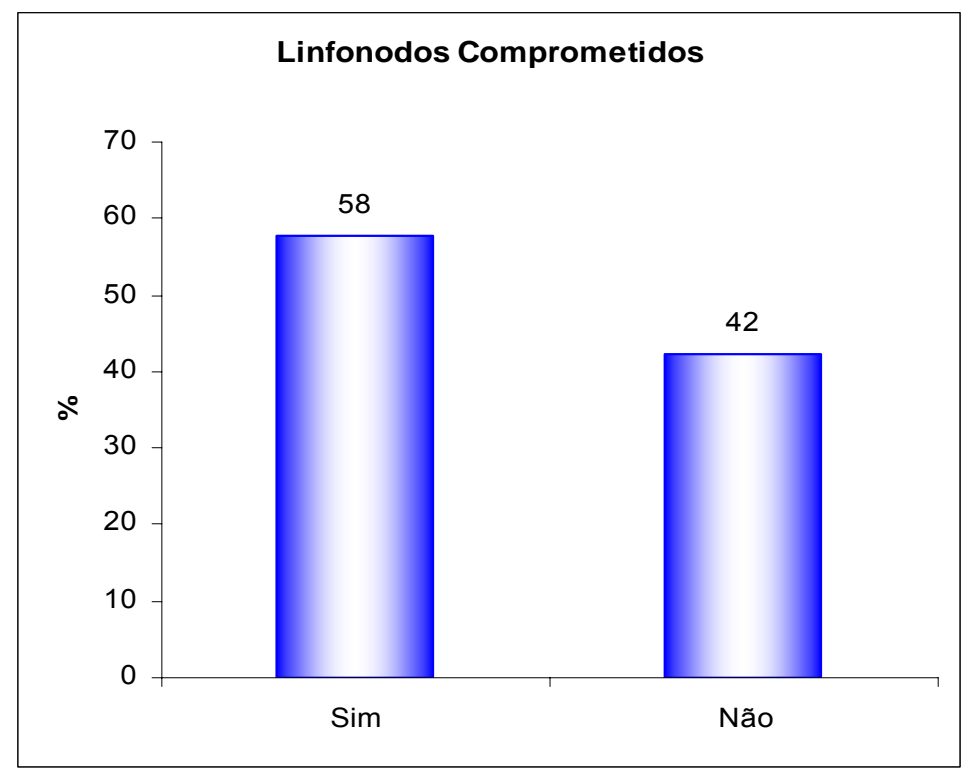

Figura 14: Distribuição do comprometimento ganglionar

Para essa variável houve diferença estatística significante de acordo com o teste de Logrank ( $p=0,004)$. Em 27 doentes $(30 \%)$ havia de um a três linfonodos comprometidos pela neoplasia e em 25 (27,8\%) foram encontrados mais de quatro linfonodos com comprometimento neoplásico, perfazendo um total de 52 pacientes $(57,8 \%)$.

Invasão vascular, linfática ou perineural estava ausente em 48 pacientes $(53,3 \%)$, sendo detectada em outros $42(46,7 \%)$, sendo vascular em $29(32,2 \%)$, linfática em $33(36,7 \%)$ e perineural em 29 (32,2\%). Houve diferença estatística significante pelo teste de Logrank $(p=0,02)$. Na Figura 15 pode-se observar a presença ou ausência de invasão vascular, linfática ou perineural por células neoplásicas. 


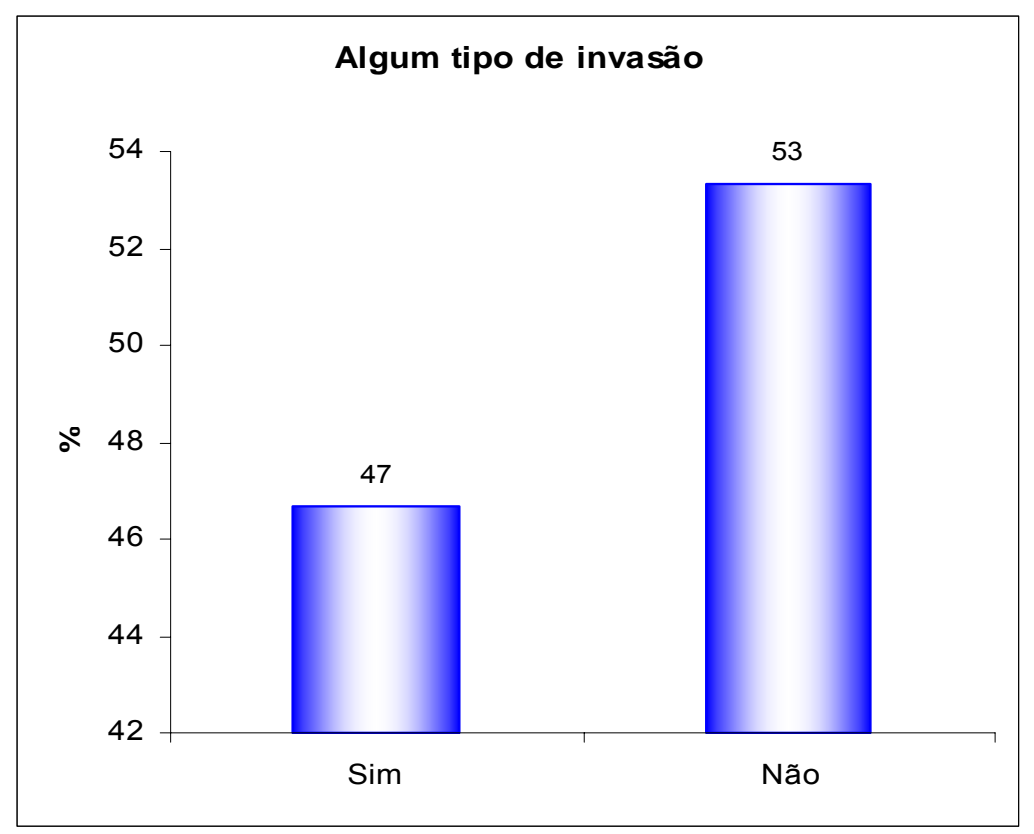

Figura 15: Presença ou não de algum tipo de invasão

Na Tabela 7 está apresentada a distribuição quanto à presença de invasão vascular, linfática e perineural, para melhor elucidação.

Tabela 7: Distribuição das invasões vascular, linfática e perineural

\begin{tabular}{lcccc}
\hline Invasão & Sim $\left(\mathbf{N}^{*}\right)$ & $\%$ & Não $\left(\mathbf{N}^{*}\right)$ & $\%$ \\
\hline Vascular & 29 & 32,2 & 61 & 67,8 \\
Linfática & 33 & 36,7 & 57 & 63,3 \\
Perineural & 29 & 32,2 & 61 & 67,8 \\
\hline
\end{tabular}

$\mathrm{N}^{*}=$ número 
Para verificar se a presença ou ausência de invasão linfática é influenciada pelo grau de penetração do tumor, realizou-se o cruzamento de dados entre essas características. Pode-se observar, na Tabela 8 , que $73 \%$ dos pacientes que possuem invasão linfática foram classificados como T4. Para confirmar a diferença existente foi realizado o teste estatístico do $x^{2}$, o qual indicou diferença significativa entre os grupos (penetração do tumor em relação à invasão linfática), com $p=0,02$. Não houve diferença estatística entre os tumores que não apresentavam algum tipo de invasão.

Tabela 8: Freqüência da invasão linfática vs. penetração do tumor

\begin{tabular}{cccc}
\hline \multirow{2}{*}{ Invasão Linfática } & \multicolumn{2}{c}{ Tamanho } & \multirow{2}{*}{ Total } \\
\cline { 2 - 3 } & T3 & T4 & \\
\hline \multirow{2}{*}{ Não } & 29 & 28 & 57 \\
& $51 \%$ & $49 \%$ & \\
Sim & 9 & 24 & 33 \\
\hline Total & $27 \%$ & $73 \%$ & \multirow{2}{*}{50} \\
\hline
\end{tabular}

$\mathrm{Na}$ avaliação quanto ao tipo de aderências entre os órgãos ressecados, constatou-se que em 37 doentes $(41,1 \%)$ elas eram de caráter inflamatório e em $53(58,9 \%)$ havia presença de tecido neoplásico, sem diferença estatística pelo teste de Logrank; $p=0,54$. 
A comparação do número de linfonodos comprometidos (LN+) entre os pacientes com aderências neoplásicas ou inflamatórias mostrou média de 6 LN+ (desvio padrão de 18,5) e 3 LN+ (desvio padrão 4,4), respectivamente, sem diferença estatística significante $(p=0,56)$.

Tentou-se também estabelecer uma relação entre o grau de penetração tumoral e o número de órgãos envolvidos (Tabela 9), mas não se detectou diferença estatística significante $(p=0,88)$.

Tabela 9: Freqüência de T3 e T4 por número de órgãos comprometidos

\begin{tabular}{|c|c|c|c|}
\hline \multirow[t]{2}{*}{ Órgãos comprometidos } & \multicolumn{2}{|c|}{ Penetração } & \multirow[t]{2}{*}{ Total } \\
\hline & T3 & T4 & \\
\hline 1 órgão & $27(71,1 \%)$ & $24(46,2 \%)$ & $51(56,7 \%)$ \\
\hline 2 órgãos & $7(18,4 \%)$ & $19(36,5 \%)$ & $26(28,9 \%)$ \\
\hline 3 órgãos & $4(10,5 \%)$ & $9(17,3 \%)$ & $13(14,4 \%)$ \\
\hline Total & $38(42,2 \%)$ & $52(57,8 \%)$ & $90(100 \%)$ \\
\hline
\end{tabular}




\subsection{Da sobrevida}

A análise da sobrevida e da recidiva foi feita somente entre os 76 $(84,4 \%)$ pacientes que foram submetidos à ressecção R0. As recidivas estavam localizadas preferencialmente na pelve em oito pacientes $(10,5 \%)$ e fígado em sete $(9,2 \%)$, como pode se observar na Tabela 10.

Tabela 10: Freqüência da localização das recidivas

\begin{tabular}{lccc}
\hline Local & $\mathbf{N}^{\circ}$ de pacientes & $\begin{array}{c}\text { \% em relação } \\
\text { a Ro }\end{array}$ & $\begin{array}{c}\text { \% em relação ao } \\
\text { total de recidivas }\end{array}$ \\
\hline Pélvica & 8 & 10,5 & 30,8 \\
Fígado & 7 & 9,2 & 27 \\
Carcinomatose & 4 & 5,3 & 15,4 \\
Fígado e pulmão & 3 & 4 & 11,5 \\
Pulmão & 2 & 2,6 & 7,7 \\
Hilo hepático & 1 & 1,3 & 3,8 \\
Calota craniana & 1 & 1,3 & 3,8 \\
\hline Total & $\mathbf{2 6}$ & $\mathbf{3 4 , 2}$ & $\mathbf{1 0 0}$ \\
\hline
\end{tabular}

Ocorreram recidivas em 26 doentes (34,2\%), diagnosticadas em tempo que variou de 3,8 a 8,8 meses (média de 6,4 meses).

Levando-se em conta apenas os pacientes tratados por cirurgia pretensamente curativa (com ausência de tumor residual), o tempo médio de sobrevida livre da doença foi de 29,7 meses, e a influência de algumas variáveis foi avaliada pela curva de Kaplan-Meier ${ }^{41}$. 
A fim de se verificar a influência das variáveis individualmente, estimou-se a sobrevivência para cada categoria através das curvas estimadas e do teste de comparação das curvas de sobrevivência (teste de Logrank). Contatou-se diferença estatística significante $(p<0,05)$ para as variáveis penetração do tumor, número de linfonodos comprometidos, presença de invasão (vascular, linfática e perineural) e local do tumor (cólon $\mathrm{x}$ reto). As figuras que representam as curvas de sobrevivência estimada para essas variáveis são apresentadas a seguir.

Na Figura 16 observa-se que a sobrevida dos pacientes com tumores T4 (tumor que ultrapassa o peritônio visceral e invade outros órgãos e/ou estruturas vizinhas, com confirmação histopatológica de aderência neoplásica) foi menor em comparação aos tumores T3 (tumor que invade além da muscular própria, sem ultrapassar a subserosa ou os tecidos desperitonizados pericólicos ou perirretais).

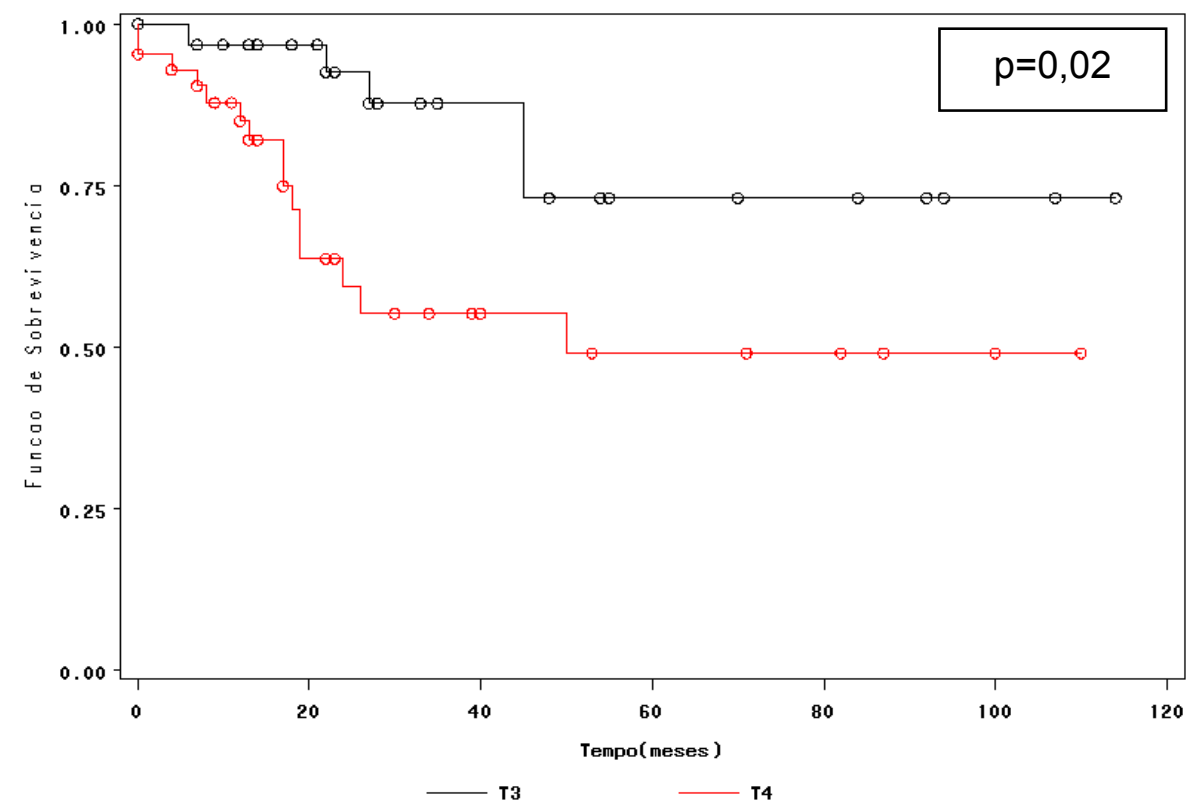

Figura 16: Sobrevivência estimada comparando a profundidade do tumor (T3 vs. T4) 
Outra forma fácil de representar a diferença entre essas variáveis é através do BOXPLOT, como se pode observar na Figura 17.

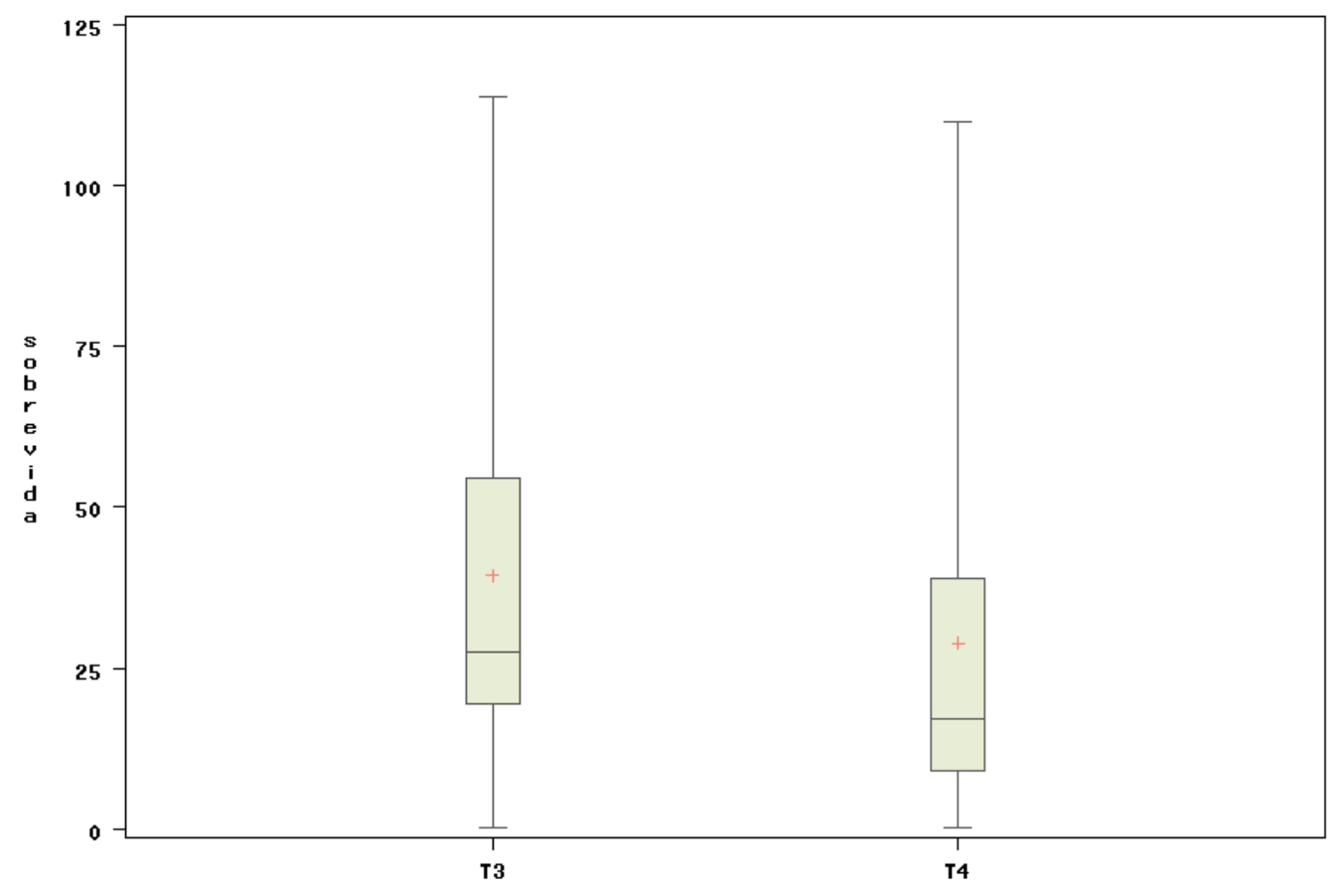

Figura 17: BOXPLOT do tempo de sobrevivência em relação à profundidade do tumor 
Na Figura 18 está apresentada a curva que representa a sobrevida em função dos linfonodos comprometidos com células neoplásicas.

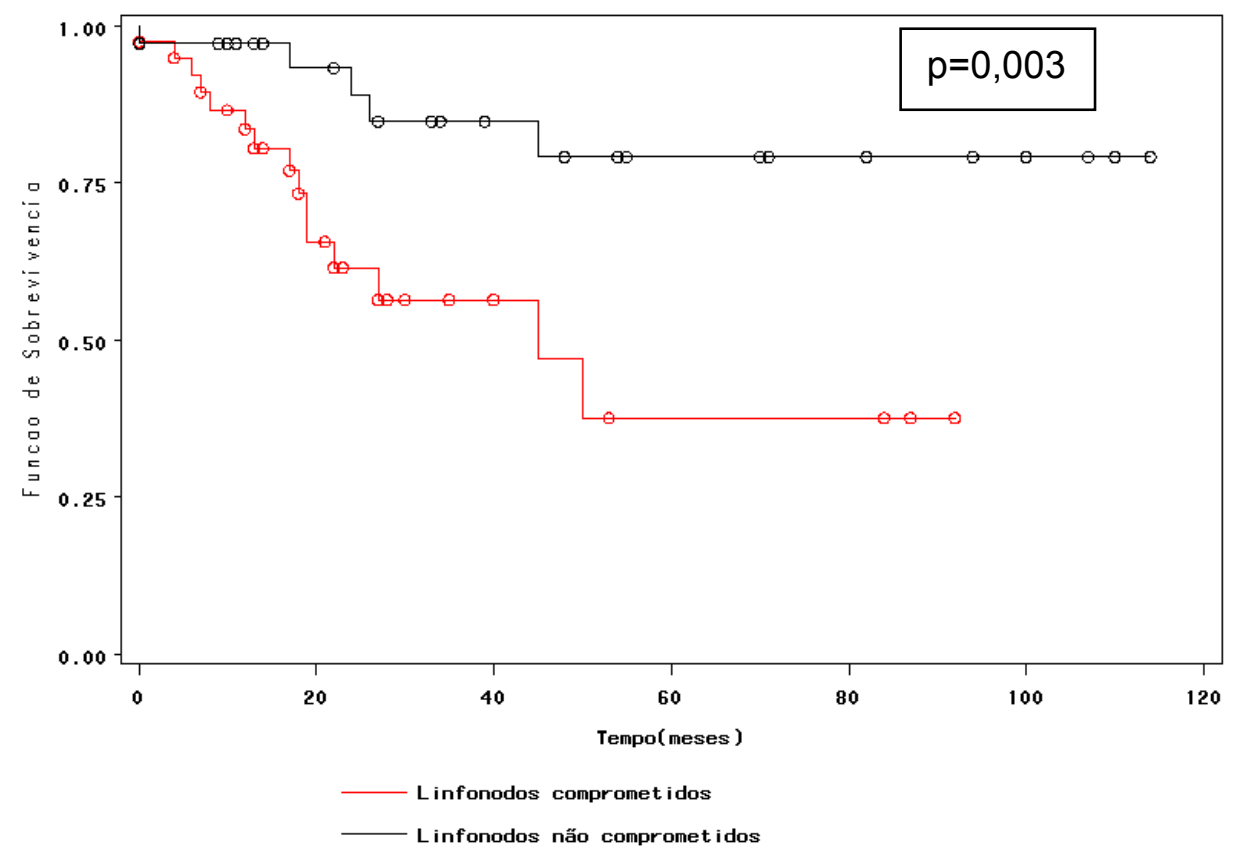

Figura 18: Sobrevivência estimada considerando a ausência ou presença de linfonodos comprometidos

Para o estudo dos linfonodos foi também utilizado o modelo de regressão de $\operatorname{Cox}^{42}$ e ajustado um modelo de riscos proporcionais e fração de cura, uma extensão do modelo de $\operatorname{Cox}^{42}$ proposta por Tsodikov ${ }^{43,44}$.

Os pacientes com um a três linfonodos comprometidos pela neoplasia tiveram chance de óbito 3,7 vezes maior que aqueles sem linfonodos comprometidos $(p=0,01)$. Por sua vez, os pacientes com quatro ou mais linfonodos comprometidos tiveram chance de óbito 5,5 vezes superior aos pacientes sem comprometimento $(p=0,001)$. 
A representação desses dados em BOXPLOT está na Figura 19.



Figura 19: BOXPLOT do tempo de sobrevivência em relação à existência de linfonodos comprometidos 
Na curva seguinte (Figura 20) encontra-se a sobrevida em função da presença ou ausência de invasão vascular, linfática e perineural.

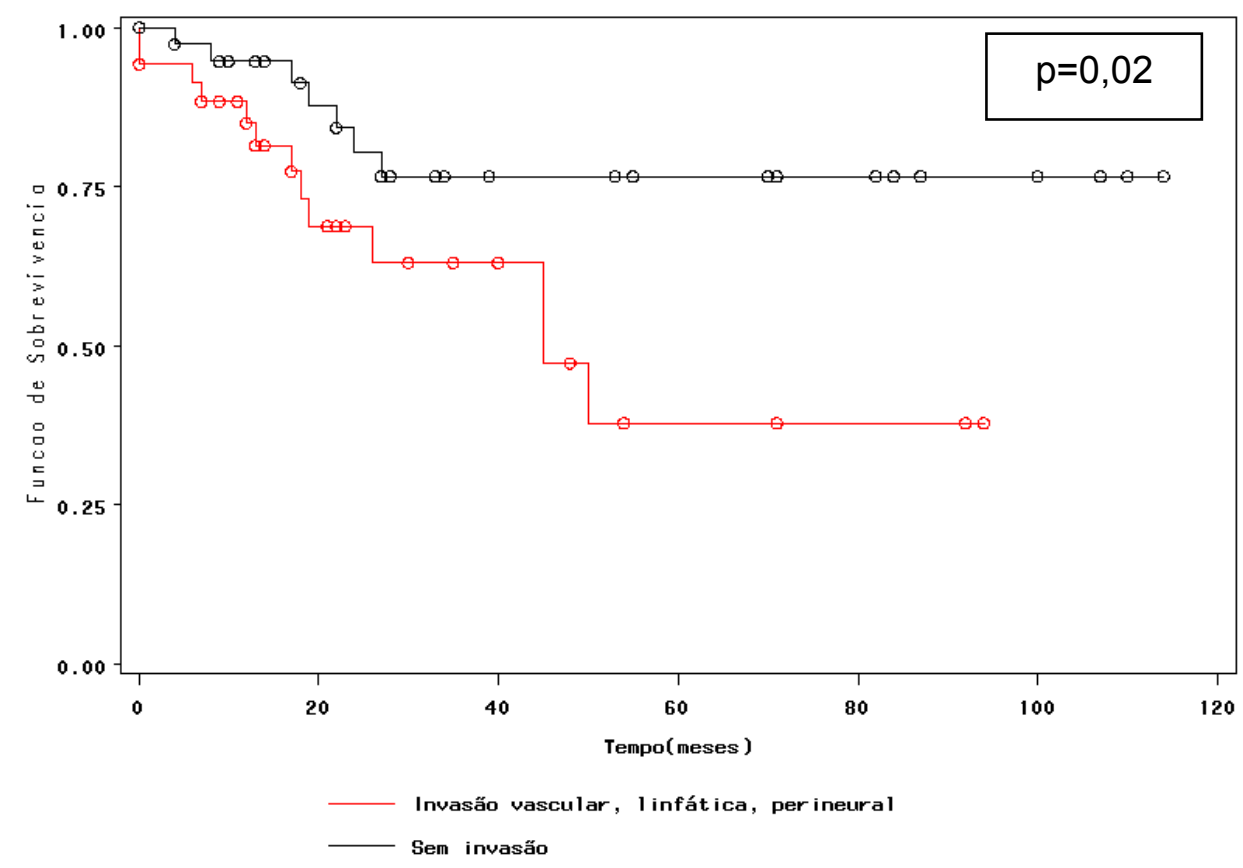

Figura 20: Sobrevivência estimada considerando a ausência ou a presença de invasão vascular, linfática e perineural 
Mais uma vez, a análise estatística demonstrou que a sobrevida de pacientes sem comprometimento neoplásico vascular, linfático e/ou perineural foi maior em relação à observada entre aqueles com invasão. Esses dados também podem ser verificados pelo BOXPLOT, na Figura 21.

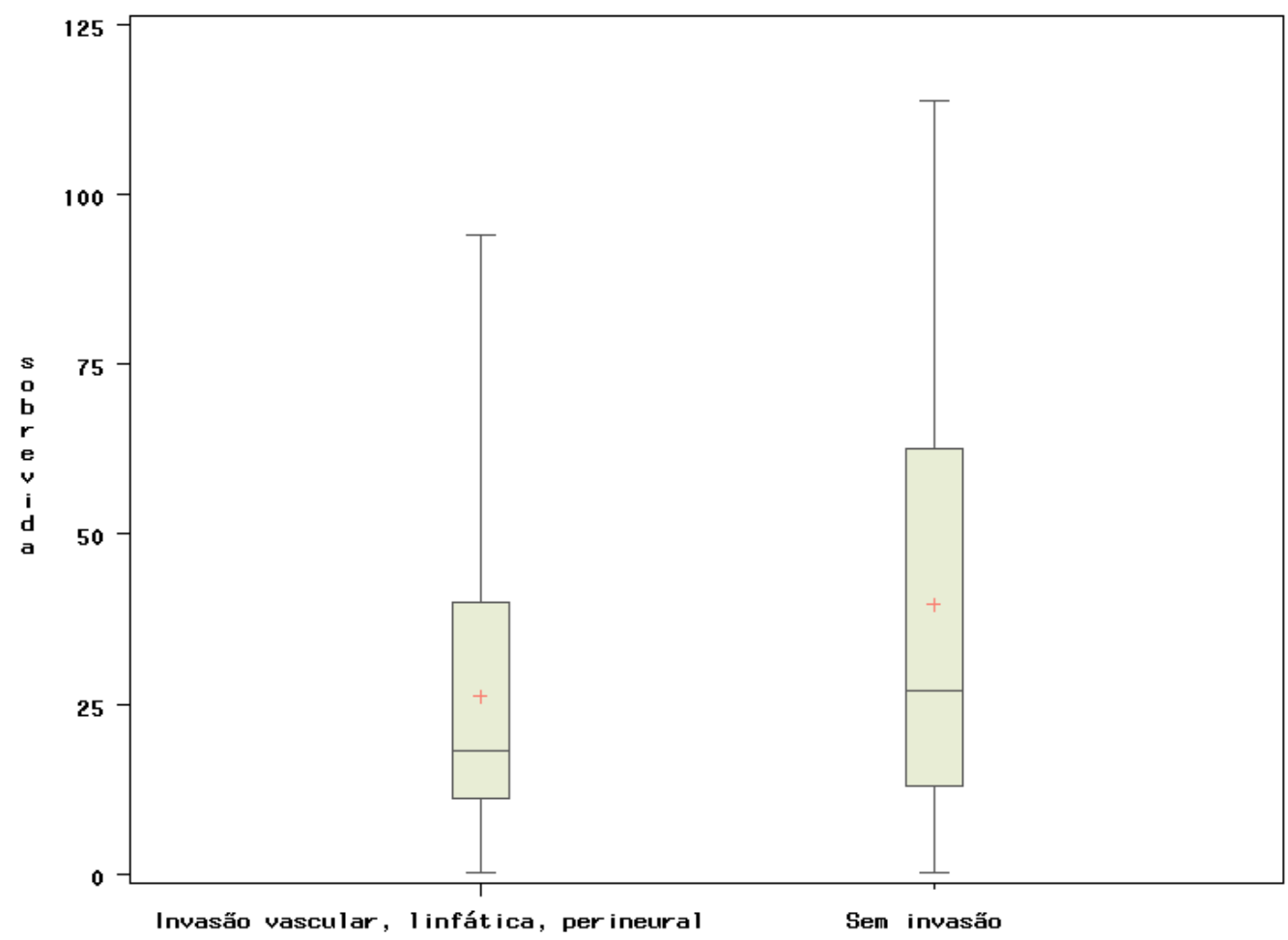

Figura 21: BOXPLOT do tempo de sobrevivência em relação à variável invasão 
Foi, também, estimada a curva de Kaplan-Meier ${ }^{41}$ para sobrevida comparando a localização do tumor no cólon em relação ao reto, como mostrado na Figura 22.

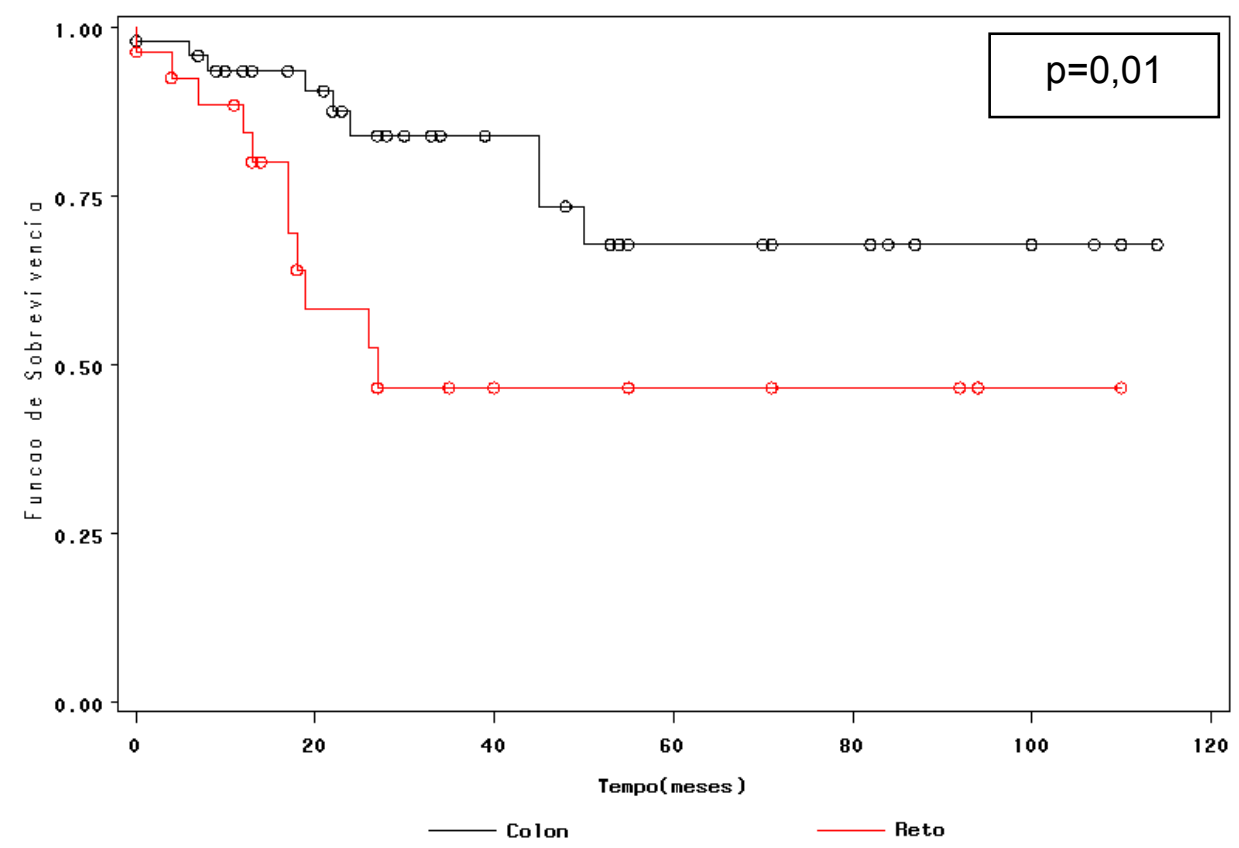

Figura 22: Sobrevivência estimada considerando a variável local do tumor: cólon vs. reto

Verifica-se que aqueles indivíduos com tumor primário localizado no reto apresentaram prognóstico pior em relação àqueles com tumores localizados nos segmentos colônicos. Isto também pode ser avaliado pelo BOXPLOT, apresentado na Figura 23. 


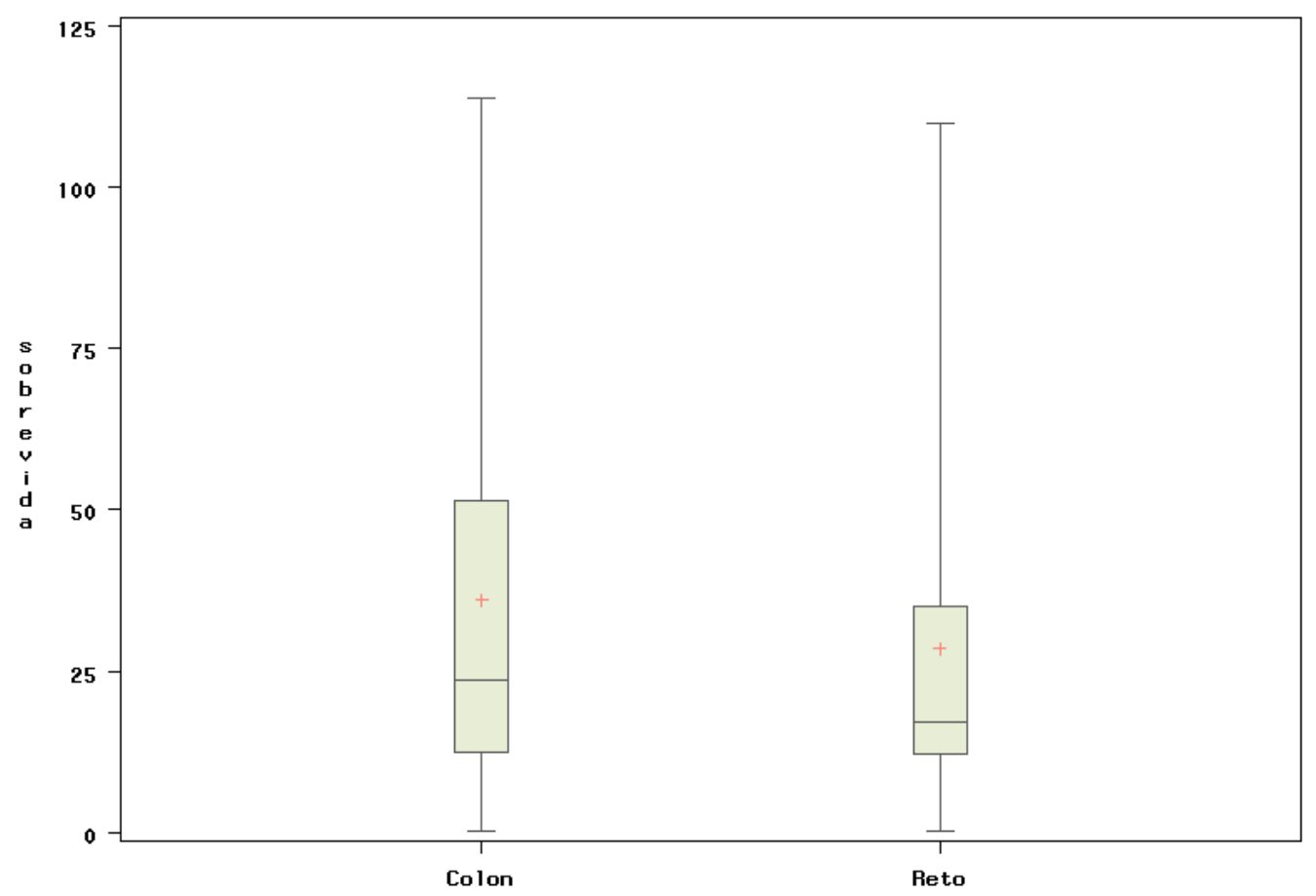

Figura 23: BOXPLOT do tempo de sobrevivência em relação ao local do tumor

$\mathrm{Na}$ Tabela 11 estão listadas as variáveis que não demonstraram diferença estatística significante em relação à sobrevida dos pacientes.

Tabela 11: Relação das variáveis que não influenciaram a sobrevida

\begin{tabular}{lc}
\hline \multicolumn{1}{c}{ Variável } & Valor de $\mathbf{p}$ \\
\hline Aderência neoplásica vs. inflamatória & 0,54 \\
Transfusão de sangue vs. sem transfusão & 0,13 \\
Número de órgãos retirados (1 vs. 2 vs. 3 ou mais órgãos) & 0,80 \\
Grau de diferenciação do tumor (B vs. M vs. P)* & 0,19 \\
Tipo histológico (epitelial vs. tubular vs. túbulo-viloso) & 0,78 \\
\hline
\end{tabular}

* $B=$ bem diferenciado $M=$ moderadamente diferenciado $P=$ pouco diferenciado 
Essas variáveis estão demonstradas a seguir, através de suas respectivas curvas de Kaplan-Meier ${ }^{41}$. Na Figura 24 pode-se observar que a curva da variável aderência inflamatória se aproxima da curva da variável aderência neoplásica, sem diferença estatística significante $(p=0,54)$.

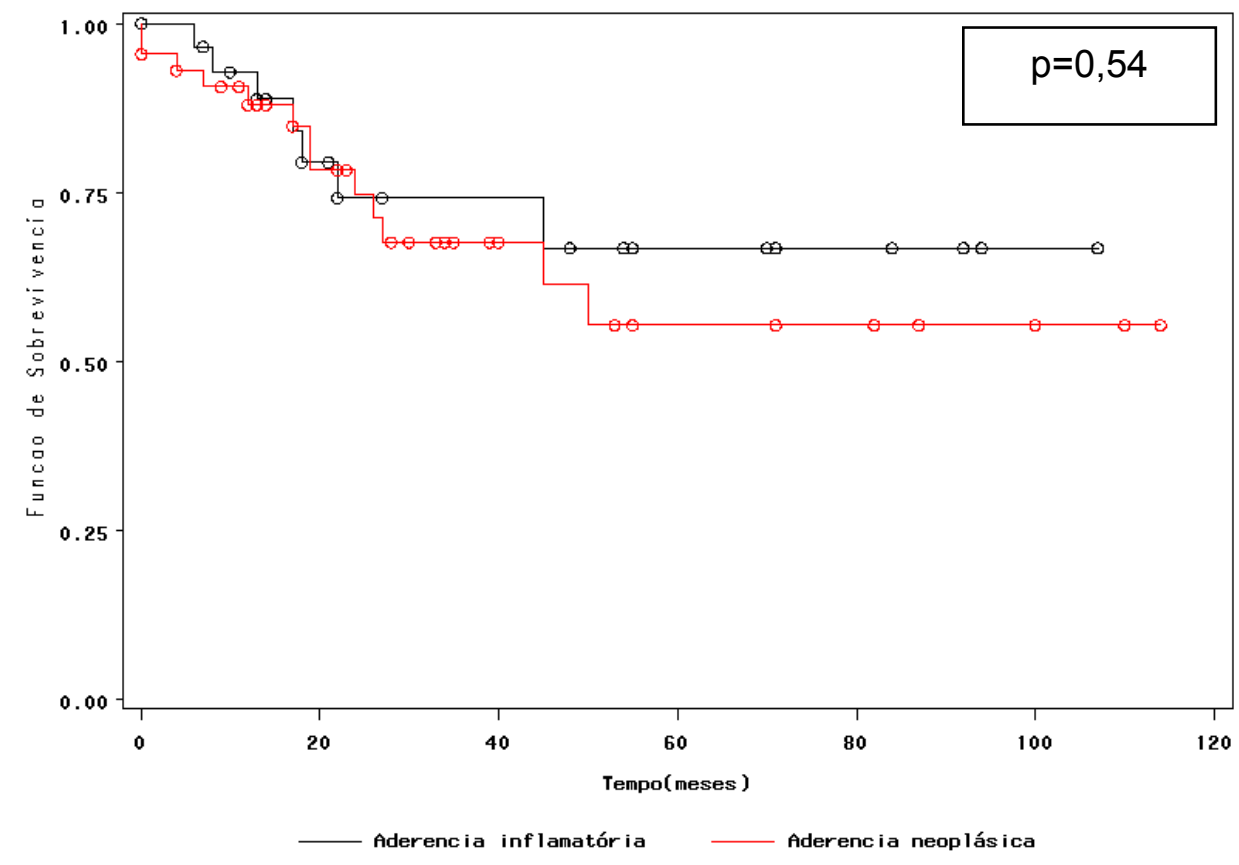

Figura 24: Sobrevida em relação à aderência inflamatória vs. aderência neoplásica

As Figuras 25 e 26 representam a variável transfusão sangüínea, comparando-se a realização ou não de transfusão (Figura 25) e a quantidade de unidades transfundidas (Figura 26). 


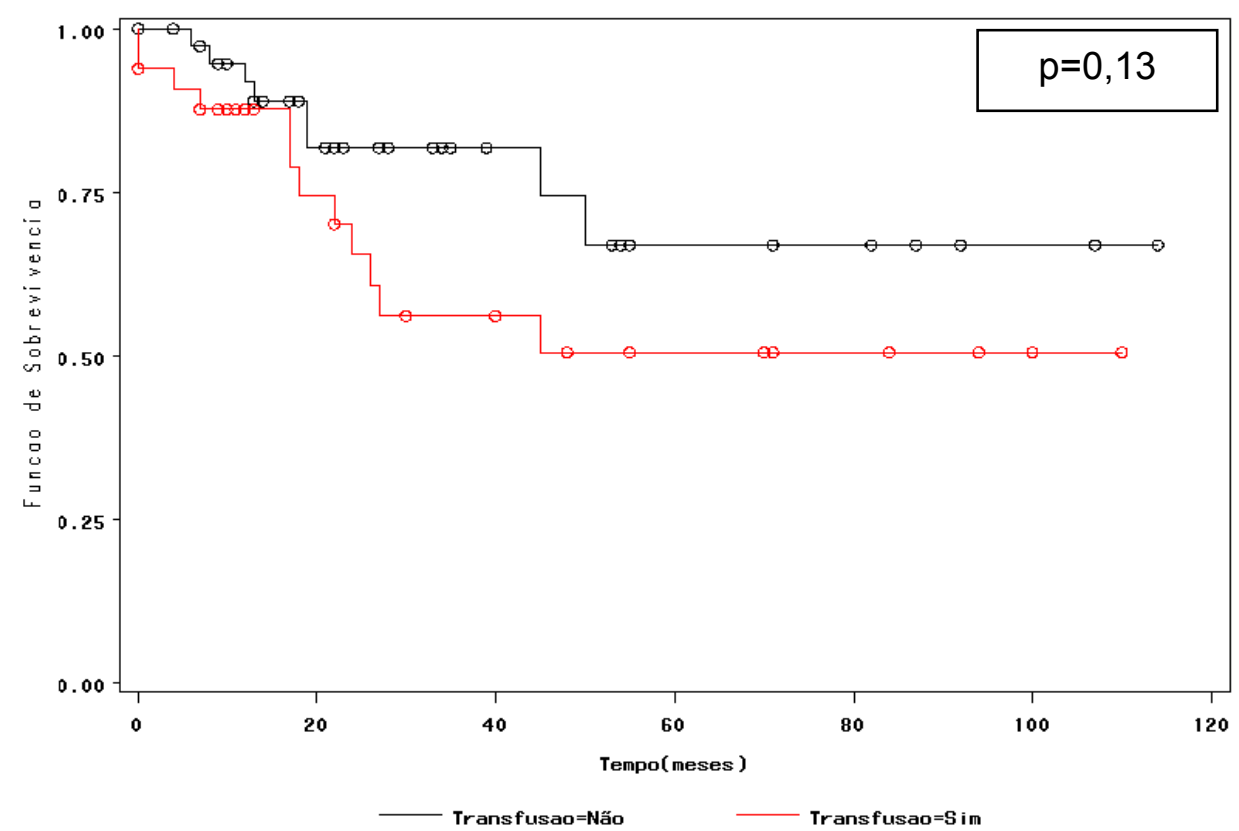

Figura 25: Sobrevida em relação à realização ou não de transfusão sangüínea

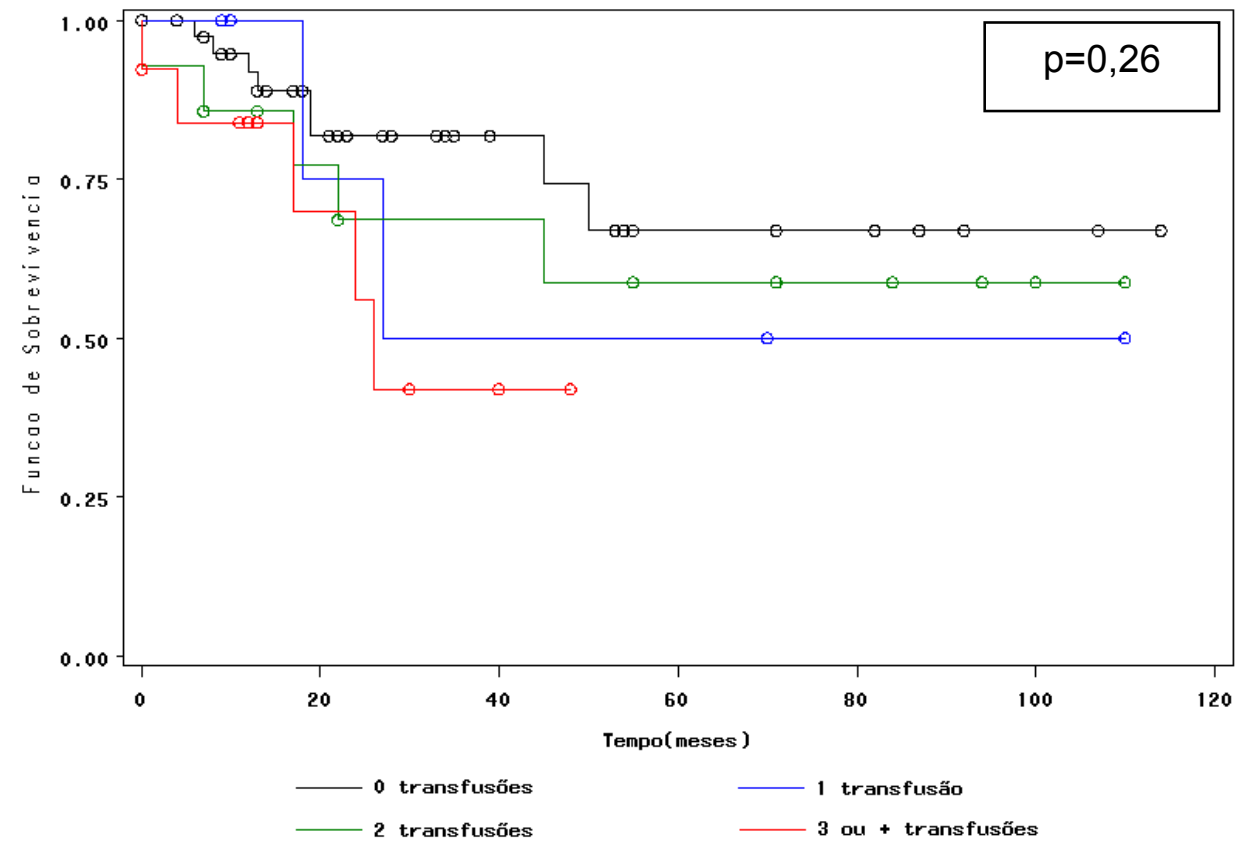

Figura 26: Sobrevida em relação à quantidade de unidades de sangue transfundidas 
Como se pode observar, nas duas curvas de Kaplan - Meier ${ }^{41}$ anteriores, elas se aproximam e os dados não apresentaram diferença estatística significante.

Na Figura 27, nota-se que o número de órgãos retirados em monobloco junto com o tumor primário não influenciou significativamente a sobrevida de cinco anos, como apresentado nessa curva de Kaplan - Meier ${ }^{41}$.

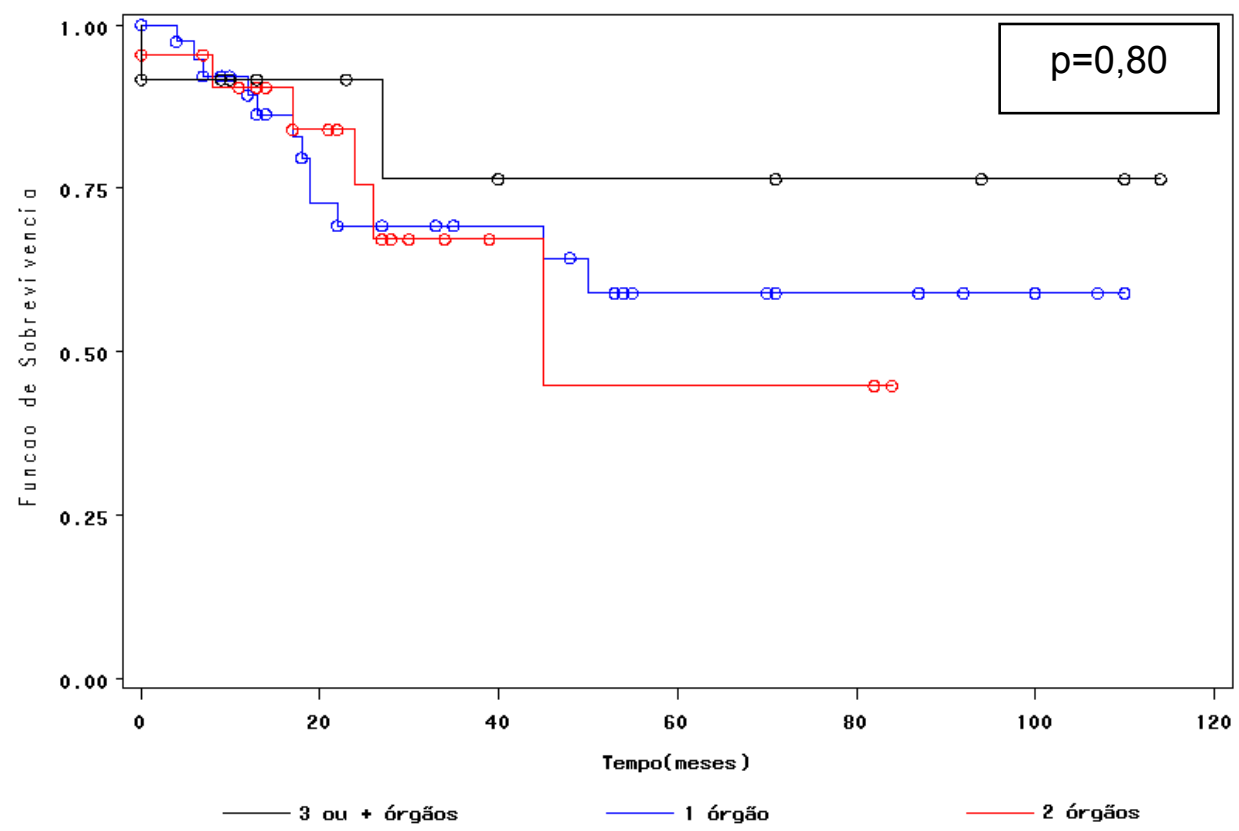

Figura 27: Sobrevida em relação ao número de órgãos ressecados junto com o tumor primário 
Na Figura 28 está demonstrada a sobrevivência em cinco anos, comparando-se os graus de diferenciação do tumor (bem diferenciado, moderadamente diferenciado ou pouco diferenciado). Foi utilizado o teste de Logrank para avaliar o impacto na sobrevida que acusou $p=0,19$, portanto, não houve significância estatística.

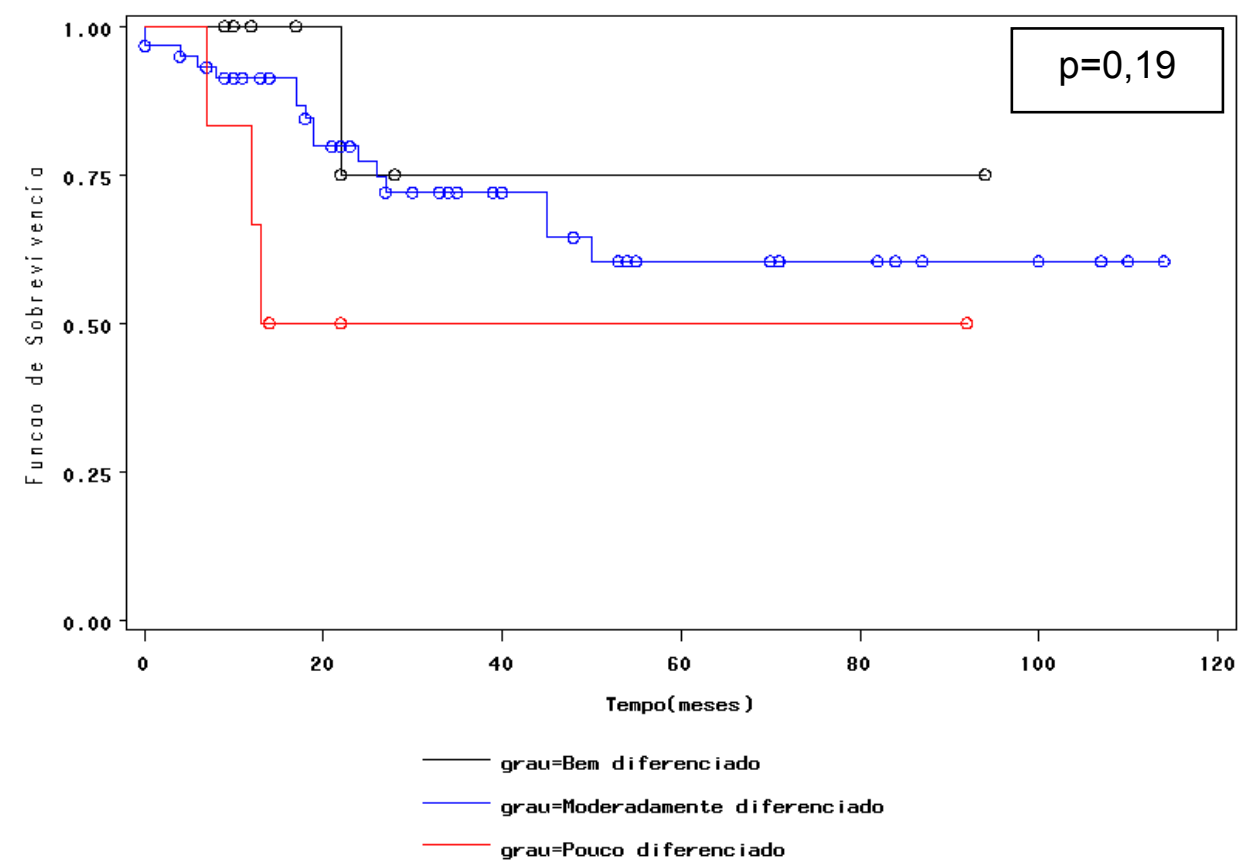

Figura 28: Sobrevida em relação ao grau de diferenciação (bem diferenciado vs. moderadamente diferenciado vs. pouco diferenciado) 
Outra variável que não apresentou diferença estatística significante, $(p=0,78)$ foi o tipo histológico. Esses resultados estão na Figura 29.

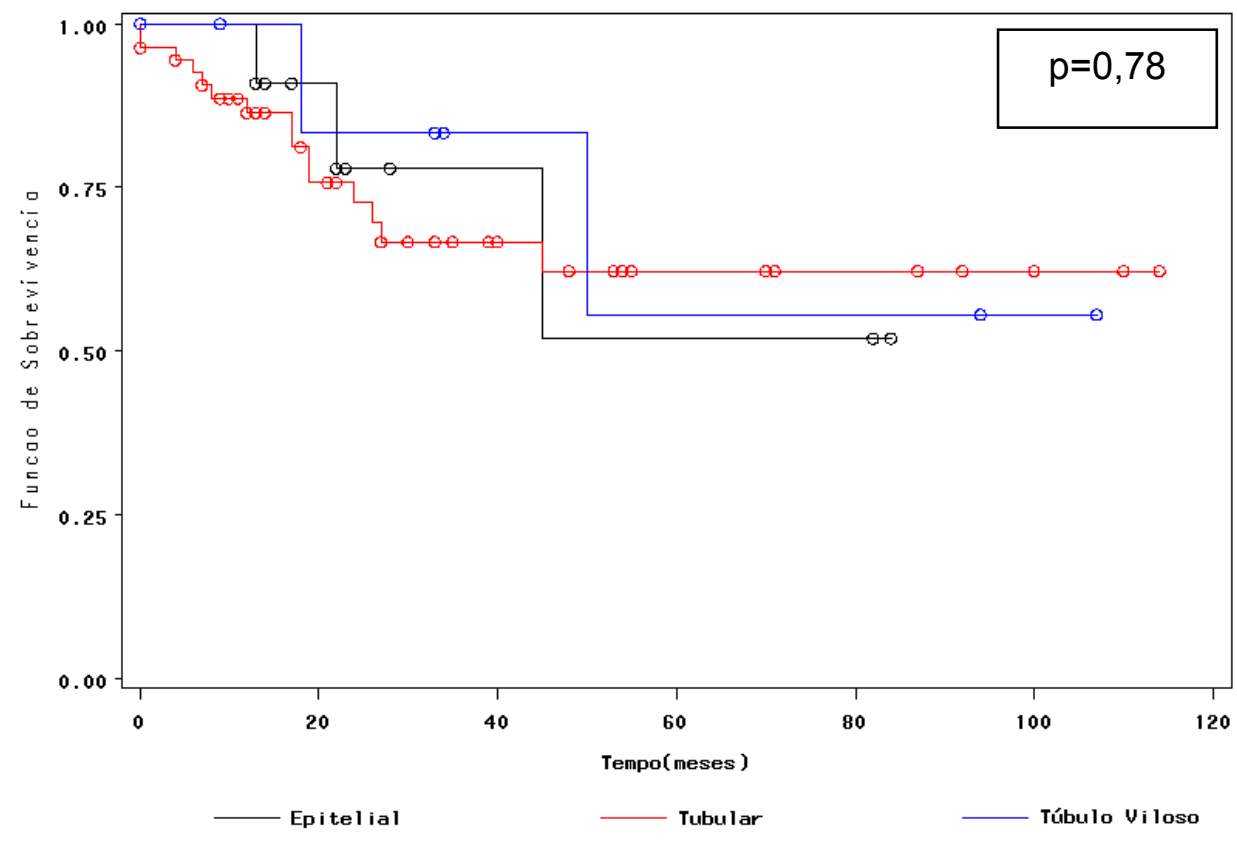

Figura 29: Sobrevida em relação ao tipo histológico (adenoma tubular vs. túbulo viloso vs. epitelial) 
Na Figura 30 pode-se apreciar a curva de Kaplan-Meier ${ }^{41}$ estimada para a sobrevida global. Realizou-se a curva de sobrevida levando em consideração todas as variáveis citadas anteriormente para estimar a sobrevivência em cinco anos. Com isso foi possível verificar que a estabilidade da sobrevida em 60 meses (cinco anos) foi de 0,61, ou seja, $61 \%$ dos pacientes atingiram esse tempo de evolução. Esta curva vem corroborar os dados citados inicialmente, cuja taxa de sobrevida aproximase de $60 \%$, com $p<0,001$.

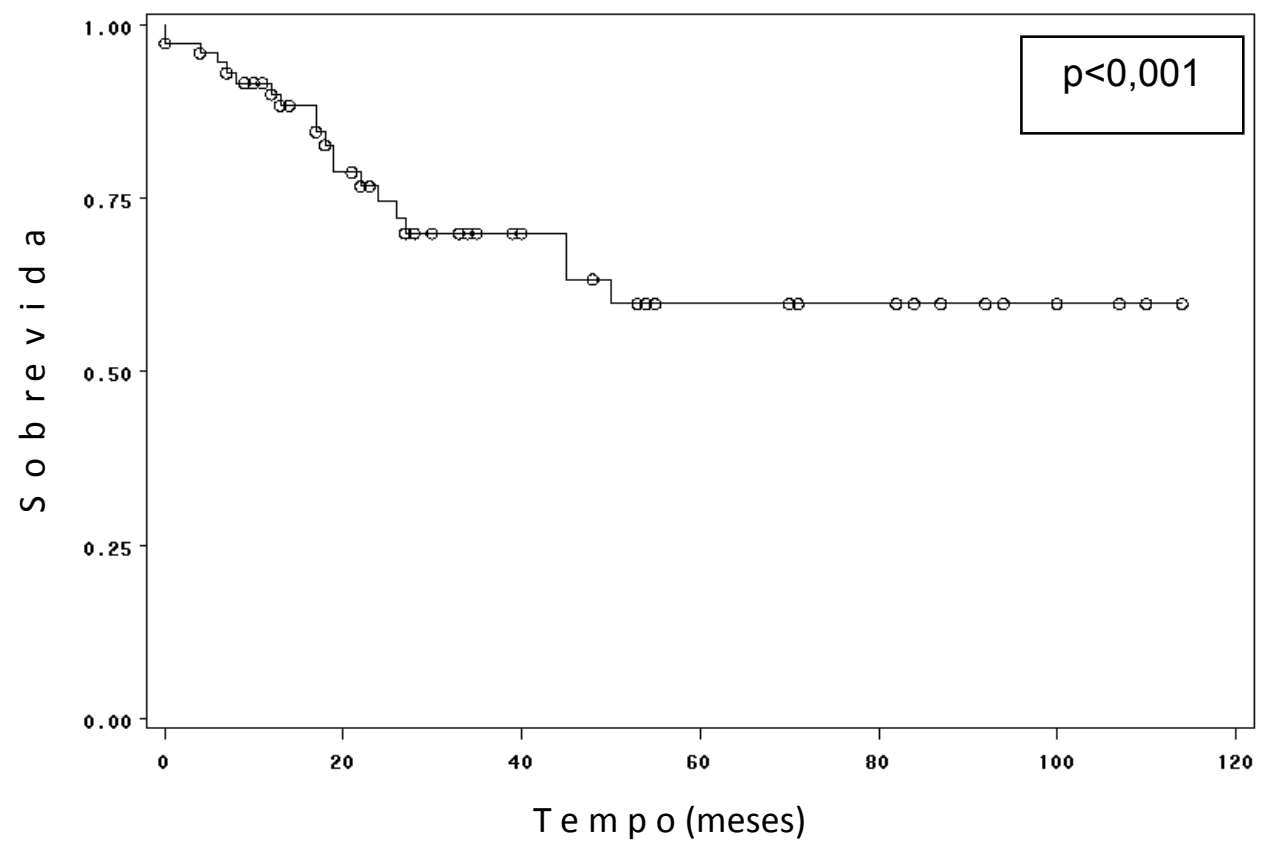

Figura 30: Sobrevida global estimada (em meses)

Ocorreram recidivas em $32,4 \%$ dos pacientes que foram submetidos à cirurgia pretensamente curativa, e na taxa de sobrevida global este foi o fator de pior prognóstico com $\mathrm{p}<0,001$. 
A Tabela 12 contém um resumo dos resultados, onde são apresentadas as variáveis que influenciaram na sobrevida de cinco anos em operações pretensamente curativas, com diferença significante na análise estatística, observando o intervalo de confiança de 95\% $(p<0,05)$.

Tabela 11: Variáveis que interferiram na sobrevida de cinco anos

\begin{tabular}{lccc}
\hline Parâmetro & Categoria & $\mathbf{N}^{\circ}$ de pacientes (\%) & $\mathbf{p}$ \\
\hline Linfonodos * $^{*} \underline{\text { Sim }}$ & Não & $\underline{52(57,8)}$ & $\underline{0,004}$ \\
Profundidade & T3 & $38(42,2)$ & 0,004 \\
Local do tumor & $\underline{\text { T4 }}$ & $38(42,2)$ & 0,017 \\
& Cólon & $\underline{52(57,8)}$ & $\underline{0,017}$ \\
Invasão & $\underline{\text { Reto }}$ & $\underline{59(65,6)}$ & 0,017 \\
& Vascular & $29(32,2)$ & $\underline{0,017}$ \\
& $\underline{\text { Linfática }}$ & $\underline{33(36,7)}$ & 0,025 \\
& Perineural & $29(32,2)$ & 0,025 \\
\hline
\end{tabular}

Linfonodos*: linfonodos com comprometimento neoplásico 





O câncer colorretal (CCR) constitui a segunda neoplasia maligna mais freqüente no mundo, estimando-se que existam 2,4 milhões de pessoas vivas com diagnóstico estabelecido. Ele determina uma sobrevida média global que varia de $40 \%$ a $50 \%$, não se observando grandes diferenças entre países desenvolvidos e em desenvolvimento ${ }^{2}$.

O tratamento do CCR em estágios precoces está associado com maiores índices de cura, determinando menores taxas de recidiva e maior sobrevida livre da doença. Dessa forma, o rastreamento visando o seu diagnóstico em fases iniciais assume papel fundamental nos resultados de seu tratamento ${ }^{13,24,47}$.

Os tumores colorretais se desenvolvem lentamente durante alguns anos, crescendo em direção à luz do órgão e se aprofundando na espessura da parede intestinal. Progressivamente, pode ocorrer comprometimento linfonodal regional e também de órgãos ou estruturas adjacentes. Nesses casos, a retirada em monobloco de todas as vísceras e estruturas envolvidas constitui o meio apropriado para controlar a neoplasia ${ }^{24,30}$.

Formas localmente avançada do CCR são diagnosticadas em cerca de $10 \%$ dos pacientes, existindo índices entre $5 \%$ e $22 \%$ na literatura ${ }^{8,23,48}$. Essa incidência varia de acordo com características próprias de cada 
instituição e não depende da inclusão de doentes submetidos à cirurgia radical ou paliativa ${ }^{49}$.

Algumas variáveis clínicas e morfológicas têm sido continuamente relacionadas ao prognóstico do $\mathrm{CCR}^{50,51,52,53}$. Entre as primeiras, merecem especial referência a idade, o sexo e o local da neoplasia. Entre as morfológicas, tamanho, forma e o envolvimento circunferencial do intestino constituem características macroscópicas de maior interesse.

No presente levantamento, 90 doentes apresentavam tumores T3 ou T4 aderidos a órgãos e/ou estruturas adjacentes intra-abdominais dentre 679 pacientes internados com CCR em período de 12 anos (1995 a 2007). O encontro de tumores localmente avançados em $13,2 \%$ dos casos confirma que este não é um evento raro e ressalta a necessidade do cirurgião estar apto para tratar de maneira adequada uma neoplasia com essas características, realizando um procedimento de maior porte.

A idade média encontrada nesse estudo foi de 59 anos e coincide com a faixa etária de maior predominância do CCR, que varia de 50 a 70 anos em nosso meio, segundo estudos epidemiológicos recentes ${ }^{54}$. Embora os padrões geográficos sejam similares entre homens e mulheres, o câncer de reto costuma ser cerca de $20 \%$ a $50 \%$ mais freqüente em homens na maioria das populações ${ }^{5}$.

No caso das ressecções multiviscerais, existe predomínio no sexo feminino, como relatado por Gebhardt et al ${ }^{55}$, que reportaram freqüência semelhante entre homens e mulheres (52,5\% e 47,5\%, respectivamente) 
em pacientes submetidos a operações-padrão e maior prevalência do sexo feminino entre aqueles tratados por cirurgias alargadas, $71(41 \%)$ homens para $102(59 \%)$ mulheres. Esses autores justificam o maior envolvimento dos órgãos genitais femininos com o cólon e o reto, devido à proximidade entre eles na cavidade pélvica. Outros autores relataram uma proporção de 2 mulheres : 1 homem e relacionaram este fato com a facilidade de acesso cirúrgico aos órgãos genitais femininos internos ${ }^{30,56}$.

De maneira similar, encontramos $61,1 \%$ mulheres contra $38,9 \%$ homens tratados por ressecções alargadas na presente série. A freqüência de lesões avançadas no cólon foi semelhante em ambos os sexos, mas no reto houve predomínio do sexo feminino ( $77 \%$ mulheres e $23 \%$ homens).

A identificação do tumor primário e a probabilidade de extensão para órgãos vizinhos foram avaliadas através do exame de colonoscopia, exame histológico do fragmento coletado, ultrassonografia abdominal, pélvica e endorretal (conforme a localização) e tomografia computadorizada, que forneceram dados fundamentais para o planejamento operatório.

O tumor primário estava localizado no reto ou sigmóide em $2 / 3$ dos casos e o 1/3 restante teve distribuição homogênea entre os cólons ascendente, transverso e descendente, de maneira semelhante à relatada por Gebhardt et al ${ }^{55}$. Neste estudo, de 173 pacientes com CCR localmente avançado, a maioria dos tumores primários (63\%) localizava-se no sigmóide, sendo a aderência com apenas um órgão, detectada em 102 pacientes, e o restante apresentando o envolvimento de mais de dois 
órgãos. Entretanto, outros relataram proporção maior de tumores primários avançados no cólon direito ${ }^{56}$.

A análise da localização do tumor em relação à sobrevida mostrou que os pacientes que tiveram o tumor primário no reto tiveram sobrevida pior em relação aos doentes com câncer nos diversos segmentos colônicos (39\% contra 61\%; $p=0,01)$. Gebhardt et al. ${ }^{55}$ relataram $48 \%$ de taxa de sobrevida para os tumores do reto e $52 \%$ para os do cólon, sem diferença estatística significante, enquanto Lehnert et al ${ }^{15}$ encontraram $41 \%$ para o reto e $49 \%$ para o cólon, com $p=0,38$.

Em estudo retrospectivo sobre a sobrevida de pacientes com CCR (independente se avançado ou não), Meguid et al. ${ }^{57}$ observaram que a incidência no cólon direito (ceco, cólon ascendente e cólon transverso) vem aumentando nos últimos anos e o prognóstico foi pior nesses casos. No total de 77.978 pacientes com CCR, acompanhados de 1988 a 2003, a sobrevida média global encontrada por eles foi de 83 meses, sendo 78 meses para o câncer do cólon direito contra 89 meses para os do cólon esquerdo (flexura esplênica ao sigmóide, excluído o reto), com diferença estatística significante.

Como o cólon estabelece relação com todos os órgãos abdominais, deve ser valorizada a anatomia topográfica de cada segmento intestinal. Dessa forma, os tumores do cólon direito podem acometer a parede abdominal ântero - lateral direita, os anexos e o útero, vasos gonadais, rim e ureter direitos, fígado e duodeno. Quando a neoplasia localiza-se no cólon transverso, pode haver envolvimento contíguo com a parede abdominal 
anterior, estômago, fígado, pâncreas e alças do intestino delgado. Uma vez no cólon esquerdo, o câncer pode invadir a parede ântero - lateral esquerda, rim e ureter esquerdos, corpo e cauda do pâncreas, baço, estômago, vasos gonadais, anexos, útero e bexiga ${ }^{21}$.

Essa relação com outros órgãos também pode ser observada quando o sítio do tumor primário é o reto. Em estudo realizado por Dulk et al ${ }^{58}$, indicava-se tratamento neo-adjuvante e cirurgia alargada quando se constatava comprometimento da parede vaginal ao exame digital. A análise dos fatores de risco na ressecção abdominoperineal demonstrou que a idade, a profundidade do tumor, a presença de linfonodos comprometidos, a ressecção do mesorreto, a distância da margem distal do tumor até a borda anal e a localização do tumor no reto foram fatores de risco independentes, com resultados adversos. Os autores relataram que a margem circunferencial da ressecção foi positiva para neoplasia em $47,8 \%$ das pacientes que sofreram ressecção parcial da parede vaginal. Concluíram ainda que, a localização anterior do câncer no reto, especificamente na mulher, mais freqüentemente requer regressão tumoral pré-operatória e/ou ressecção mais extensa para se obter margens livres.

Na presente série, os órgãos e estruturas que mais freqüentemente foram ressecados em monobloco com o tumor primário foram o intestino delgado $(19,8 \%)$, a bexiga $(16,4 \%)$, o útero $(13 \%)$, os ovários com as trompas $(11,2 \%)$ e a vagina $(9,5 \%)$. De maneira geral, esses números guardam semelhança com as freqüências relatadas por outros autores ${ }^{15}$. Por outro lado, não encontramos diferença estatística significante quanto ao 
impacto na sobrevida, na dependência do número de órgãos ressecados conjuntamente $(p=0,80)$.

Segundo relatos de Franko et al ${ }^{59}$, o tempo de sobrevida não se alterou com o número de órgãos ressecados. Esses autores encontraram também que o aumento do risco de complicações está associado com o maior número de anastomoses e não com a ressecção multivisceral, nem mesmo se utilizada a cirurgia citorredutora e a quimioterapia intraperitoneal com hipertermia.

Embora quase metade dos pacientes tenha necessitado transfusão sangüínea $(41 ; 45,6 \%)$, esse fato não influenciou substancialmente na sobrevida, conforme citado em outros trabalhos ${ }^{11,15}$. Entretanto, série recente demonstrou que a transfusão sangüínea representou fator de pior prognóstico em operações multiviscerais em estudo de 323 pacientes, 53 $(16,4 \%)$ dos quais submetidos à cirurgia multivisceral em que tamanho do tumor, profundidade da invasão, duração do ato operatório, perda e reposição sangüínea influenciaram o prognóstico ${ }^{60}$.

Através de análise multivariada, Lehnert et al. ${ }^{15}$ não encontraram significância prognóstica para o número de órgãos ressecados e a realização de transfusão sangüínea em 201 pacientes operados, mas apontam como fatores prognósticos significantes a perda sangüínea intraoperatória, idade acima de 64 anos e estágio patológico da lesão.

Observando o grau de penetração do tumor (parâmetro $\mathrm{T}$ da classificação TNM $\left.{ }^{39}\right)$, foram detectadas 38 neoplasias T3 $(42,2 \%)$ e 52 T4 
(57,8\%). A curva estimada de sobrevivência revelou diferença importante para tumores T4 em relação aos T3, com piora da sobrevida quanto mais se aprofunda na parede do cólon ou reto (40\% e 60\% respectivamente com $p=0,02)$, resultados semelhantes aos citados na literatura $4,29,61$.

Hoje se reconhece que os adenocarcinomas mucinosos do cólon e reto estão freqüentemente associados com pior sobrevida ${ }^{62}$. Em referência aos tipos histológicos encontrados, o mais freqüente tipo histológico encontrado foi o tubular $(75,6 \%)$, vindo a seguir o tipo epitelial (mucinoso ou mucocelular) em $15,6 \%$ e o túbulo-viloso em $8,8 \%$ dos doentes. A análise isolada desta variável não demonstrou impacto na curva de sobrevida $(p=0,07)$, corroborando com dados semelhantes descritos por Vieira et al ${ }^{18} \mathrm{e}$ por Yun et al ${ }^{63}$.

Quanto ao grau de diferenciação do tumor, a grande maioria das lesões era representada por tumores moderadamente diferenciados (74; 82,2\%), e não encontramos diferença estatística em comparação aos tumores pouco ou bem diferenciados, de maneira similar à relatada por Araujo ${ }^{11}$ e Lehnert ${ }^{15}$.

Diversas publicações têm reportado a presença de aderências neoplásicas entre os diversos órgãos envolvidos em taxas de $40 \%$ a $80 \%$ dos casos 17, 64, 65. Nesta série, a presença de aderências neoplásicas $(58,9 \%)$ ou inflamatórias $(41,1 \%)$ determinou prejuízo da sobrevida de cinco anos na primeira categoria ( $47 \%$ de taxa de sobrevida para as aderências neoplásicas e 53\% para as inflamatórias), embora não tenha atingido 
significância estatística $(p=0,54)$. Eventualmente, a apreciação de um maior número de pacientes poderia mostrar de maneira mais clara o impacto de células neoplásicas provocando aderência entre órgãos.

Durante o ato operatório é impossível distinguir a verdadeira natureza das aderências, razão pela qual a estrutura aderida não deve ser separada do tumor primário, mesmo quando se suspeitar que aderências inflamatórias possam estar mimetizando as neoplásicas ${ }^{66}$. A imposição de não separar os órgãos aderidos e a necessidade de se proceder à ressecção alargada são reconhecidas há muitos anos como medidas efetivas para obter a cura do paciente com tumor localmente invasivo.

Em 1959, Butcher e Spjut ${ }^{67}$ relataram 5\% de sobrevida em cinco anos em pacientes submetidos à ressecção limitada contra 33\% de sobrevida em cinco anos naqueles tratados por ressecção alargada. Por sua vez, Hunter et al ${ }^{30}$ compararam os resultados do tratamento realizado por colectomia padrão, ressecção alargada e colectomia com separação de órgãos aderidos, em portadores de CCR localmente avançado, reportando índices de sobrevida de $55 \%, 61 \%$ e $23 \%$, respectivamente. Destacaram, ainda, que esse último grupo desenvolveu alto índice de recorrência local que atingiu 69\%.

Lehnert et al ${ }^{15}$ citam uma taxa de sobrevida de $41 \%$ quando havia comprometimento neoplásico contra $58 \%$ para aderências inflamatórias $(p=0,04)$. Da mesma forma, outros também reportaram menor sobrevida com aderências neoplásicas em comparação às inflamatórias, como Gentil et al ${ }^{68}$ (28,3\% vs. $\left.42,1 \%\right)$ e Silva et al ${ }^{21}$ (18\% vs. 57\%). 
A presença de embolização vascular, linfática e a invasão perineural por células neoplásicas foram detectadas em 42 doentes $(46,7 \%)$, sendo vascular em 29 (32,2\%), linfática em 33 (36,7\%) e perineural em 29 (32,2\%). Dentre elas, a que teve maior influência negativa na sobrevida foi a embolização linfática $(p=0,02)$. Dados semelhantes foram publicados por Lehnert et al em $2002^{15}$. Esses autores descrevem taxa de sobrevida de $28 \%$ quando a invasão linfática está presente contra $60 \%$ quando ela está ausente $(p=0,02)$. Esses valores são muito semelhantes aos que pudemos observar na nossa série.

Ao realizarmos o cruzamento de dados, pudemos ainda observar que dentre os pacientes com invasão linfática, $73 \%$ são tumores T4. Logo, podemos concluir que quanto mais profundo o tumor, maior a probabilidade de atingir os vasos linfáticos e disseminar as células neoplásicas, com propagação local e à distância do tumor e prejuízo na sobrevida do paciente. Como citado em trabalho recente do Memorial Sloan Kettering Cancer de Nova York ${ }^{69}$, a mortalidade global e o risco de metástases aumentam quanto maior é a invasão em profundidade do tumor. Esses autores relacionam nesse estudo a penetração do tumor com outros fatores histopatológicos significantes como metástases linfonodais, metástases à distância, invasão vascular extramural, grau de diferenciação celular e a sobrevida global. Eles observaram que aumentava a incidência de metástases, quanto mais profundo o tumor (13\% dos T3N1 tinham metástases à distância, 33\% dos T3N2, 40\% dos T4N1 e $68 \%$ dos T4N2). 
Sempre que possível, a ressecção oncológica deve compreender a exérese dos linfonodos relacionados ao segmento onde está localizado o tumor. Desde os clássicos trabalhos de Dukes ${ }^{70}$, Simpson e Mayo ${ }^{71}$, o comprometimento linfonodal é reconhecido como o fator prognóstico mais importante, incorporando esse dado à classificação para o câncer retal e do cólon. Na série aqui apresentada, a presença de comprometimento linfonodal pela neoplasia ocorreu em 52 doentes $(57,8 \%)$ e teve impacto negativo na sobrevida (sobrevida de $29 \%$ contra $70 \%$; $p=0,004$ ).

Dentre os 90 pacientes operados, 52 (57,8\%) apresentavam comprometimento neoplásico dos nódulos linfáticos, contra $38(42,2 \%)$ com linfonodos livres da neoplasia. Dos 52 com linfonodos comprometidos, $32(61,5 \%)$ também tinham aderências de caráter tumoral, enquanto somente $20(38,5 \%)$ tinham aderências de caráter inflamatório.

Chang et al. ${ }^{72}$ fizeram uma revisão sistemática utilizando as bases de dados da Medline, Scopus, Cochrane e o National Guidelines Clearinghouse para comparar a importância da avaliação do número de linfonodos ressecados em operações curativas e o número de linfonodos com comprometimento neoplásico. Cinco estudos coorte retrospectivos foram analisados, contendo 35787 pacientes de vários países. Com o número preconizado de pelo menos 12 linfonodos a serem avaliados (segundo recomendado pelo Congresso Mundial de Gastroenterologia) observou-se que apenas $37 \%$ de pacientes com CCR recebem uma avaliação adequada dos linfonodos e que a maior sobrevida está relacionada com o adequado número de linfonodos examinados. A melhora nessa sistematização resultaria 
em melhora clínica e na sobrevida dos pacientes, pois a partir dessa avaliação dos linfonodos é que se traça também a continuidade do tratamento adjuvante. Eles relatam ainda que em países como Estados Unidos, Canadá, França, Países Baixos e Suécia já existem essa preocupação de avaliar melhor os linfonodos, pois comprovadamente isso vai influenciar na sobrevida, como pudemos também demonstrar em nosso estudo. A média de linfonodos ressecados no nosso trabalho foi 21, com mediana $=16$.

Em um estudo recente, Johnson et al ${ }^{73}$ sugerem que quando considerados juntos, o número de linfonodos positivos com os linfonodos negativos, irá fornecer uma informação melhor quanto ao prognóstico, do que os linfonodos positivos somente. Eles ainda relatam que a relação entre o número de linfonodos negativos e o prognóstico difere entre pacientes com envolvimento superficial da parede do intestino, daqueles com envolvimento mais profundo da espessura da parede intestinal.

Em 1990, Eisemberg et al ${ }^{28}$ publicaram um estudo com 1042 pacientes, 58 dos quais foram submetidos à ressecção multivisceral curativa e comparou a curva atuarial de cinco anos de sobrevida livre da doença, relatando uma taxa de sobrevida de $76 \%$ entre os pacientes sem envolvimento linfonodal; entre aqueles com linfonodos positivos para neoplasia, nenhum sobreviveu cinco anos.

De maneira similar, Nakafusa et al ${ }^{60}$ reportaram 323 pacientes submetidos à cirurgia curativa para tumores pT3 - pT4, onde a presença de linfonodos positivos para neoplasia foi um fator prognóstico importante na 
sobrevida. Em artigo publicado em 2003, Le Voyer et al ${ }^{74}$ afirmaram que a sobrevida no câncer de cólon está associada com o maior número de linfonodos analisados. Para isso, relaciona à técnica cirúrgica adequada, a experiência do cirurgião, a metodologia do patologista, o maior número possível de linfonodos ressecados, bem como todo o tecido envolvido na tumoração com margens de segurança suficientes. Poeze et al ${ }^{75}$ referem como fatores preditivos mais importantes de sobrevida o estado do linfonodo e o envolvimento das margens do tumor ressecado.

No presente estudo, a variável que apresentou diferença estatística mais significante e, portanto, mais influenciou na taxa de sobrevida de cinco anos foi a presença de linfonodos com comprometimento neoplásico. Lopes et al ${ }^{36}$ relataram ter encontrado linfonodos negativos em $60 \%$ dos pacientes e nesses a sobrevida foi de $70 \%$. Desch et al ${ }^{76}$ sinalizam para o número de linfonodos ressecados e a criteriosa análise dos mesmos, como fator importante para definir prognóstico, juntamente com outros de considerável importância como invasão vascular e linfática, grau histológico, invasão perineural, que devem ser utilizados para determinar o risco e a estratégia de vigilância. Esses mesmos autores, além de outros estudos recentes ${ }^{77,78,79,80}$ ressaltam o longo tempo de seguimento que deve ser realizado com esses pacientes com CCR avançado e com prognóstico mais sombrio, devido o risco contínuo de recorrência após cinco anos de sobrevida.

Cinqüenta e dois pacientes apresentavam tumor T4, ou seja, ultrapassando a serosa, e entre eles 33 (63,5\%) tinham linfonodos já comprometidos pela neoplasia, enquanto 19 (36,5\%) ainda não apresentavam 
esse comprometimento. Dentre os pacientes com tumores T4 com linfonodos neoplásicos, $18(54,55)$ tiveram apenas um órgão ressecado conjuntamente com o tumor primário, $9(27,3 \%)$ dois órgãos ressecados em conjunto e em 6 $(18,2 \%)$ três ou mais órgãos foram ressecados em monobloco.

Dentre os 90 pacientes, a probabilidade média de sobrevida em cinco anos foi de $61 \%$, o que está de acordo com vários autores aqui apresentados ${ }^{48,60}$.

Geralmente, as ressecções alargadas se associam a maior morbidade em relação às ressecções padrão em operações colorretais, mormente em pacientes com idade mais avançada ${ }^{31,81,82}$.

Entre os 23 doentes que apresentaram intercorrências até trinta dias após a data da operação, $13(56,5 \%)$ tinham idade menor que 65 anos e $10(43,5 \%)$ tinham idade igual ou superior a 65 anos, mas não houve diferença estatística. Em um estudo prospectivo multicêntrico envolvendo 75 hospitais da Alemanha e 3756 pacientes submetidos às cirurgias para carcinomas colorretais, Marusch et al ${ }^{81}$ separaram três grupos: 64 anos ou menos, idade entre 65 e 79 anos e pacientes com mais de 80 anos. Observaram que nos mais idosos a freqüência das complicações pós-operatórias gerais $(21,5 \%, 28,6 \%$ e $41,2 \%)$ e morbidade $(36,5 \%, 42,6 \%$ e $50 \%)$ foram maiores, relacionando isso ao fato de terem encontrado uma maior proporção de tumores mais avançados nos pacientes mais idosos. Os autores concluíram que os índices de morbi-mortalidade aumentam proporcionalmente com a idade, mas são decorrentes de complicações pós-operatórias gerais, não importando se cirurgia padrão ou ressecção multivisceral. 
Na literatura, os índices de complicações pós-operatórias variam de $20 \%$ a $42 \%$, com média em torno de $30 \%{ }^{28}$. Na presente série, ocorreram complicações e mortalidade em $25,6 \%$ e $3,3 \%$ dos doentes, respectivamente. De maneira semelhante, a ocorrência de complicações fatais nesta série situou-se dentro da faixa reportada na literatura que varia entre $1,7 \%$ e $13 \%$ dos casos $^{83}$.

Segundo Vieira et al $^{18}$, registrou-se uma diminuição significativa nas taxas de morbidade no período de 1950 a 1990, que chegaram a cair $50 \%$ após a década de 80 , provavelmente devido aos progressos nos métodos de diagnóstico e estadiamento, aos cuidados pré e pós-operatórios, às unidades de terapia intensiva e à maior experiência dos profissionais.

No estudo feito por Andreoni et al ${ }^{84}$, não houve diferença estatística na taxa de morbidade observada, comparando operações padrão para o CCR com as ressecções multiviscerais quando há invasão de órgãos vizinhos $(37,5 \%$ vs $41 \%, p=0,44)$. Também relatam que a taxa total de complicações esteve associada com a transfusão sangüínea no período peri-operatório $(35,3 \%$ dos não transfundidos tiveram complicações contra $60,2 \%$ dos que receberam transfusão, $p<0,0001)$ e os pacientes que foram submetidos à ressecção multivisceral, necessitaram mais transfusões do que na cirurgia padrão $(16,3 \%$ vs $10 \%, p=0,03)$.

Yun et al ${ }^{63}$ usaram a classificação de Clavien ${ }^{85}$ para comparar as taxas de morbidade entre a cirurgia padrão e as ressecções alargadas. De acordo com essa classificação, na morbidade maior (classificação de Clavien $\geq 2)$ não houve diferença estatística significante $(0,9 \%$ para a 
cirurgia padrão vs $2,4 \%$ para a alargada) e na morbidade menor (classificação de Clavien = 1), houve diferença estatística significante $(1,9 \%$ para a cirurgia padrão vs $10,8 \%$ para a alargada, $p<0,001)$. Eles ainda concluíram que na ressecção multivisceral realizada de forma radical, cuidadosa e prudente, a expectativa é que não haja diferença na morbidade operatória, quando comparada com a ressecção padrão.

Há consenso de que as ressecções multiviscerais requerem uma equipe cirúrgica treinada e experiente uma vez que, em muitos casos, a decisão quanto à extensão da ressecção é firmada somente no intra-operatório, após a inspeção da cavidade abdominal. Essa decisão deve levar em consideração o risco de complicações e os benefícios potenciais de sobrevida ${ }^{6,22,86}$. O tipo de operação, a necessidade de tratamento neo-adjuvante (no caso da neoplasia do reto) são decisões que deverão ser baseadas nas variáveis clínicas, anatômicas e patológicas e devem incluir o toque retal, a avaliação endoscópica, exames de imagem, avaliação da dimensão óssea da pelve, volume do tumor, grau de comprometimento das estruturas vizinhas, a margem de ressecção circunferencial, no caso do reto, o envolvimento de linfonodos do meso e tudo que se relacione à extensão da doença ${ }^{78,79,80}$.

Fatores como menor tamanho do tumor primário, menor número de órgãos envolvidos, margens de ressecção livres de neoplasia, aderências inflamatórias e ausência de comprometimento linfonodal (ou pequeno número de linfonodos positivos) têm sido apontados como de valor prognóstico favorável em relação ao risco de recidiva e sobrevida ${ }^{87,} 88$. Apesar disso, o caráter inflamatório ou neoplásico das aderências e o 
número de órgãos envolvidos não influenciaram a sobrevida dos pacientes por nós acompanhados.

Wong et al. ${ }^{69}$ realizaram um estudo coorte com 796 pacientes para examinar a correlação entre a invasão em profundidade do câncer no cólon, a extensão da neoplasia e a sobrevida do paciente. Observaram também a taxa de linfonodos e as metástases à distância, o grau de diferenciação do tumor e a invasão vascular extramural por células neoplásicas. Através dos resultados e análises estatísticas puderam observar que a profundidade do tumor está fortemente relacionada com 0 envolvimento linfonodal $(p=0,0001)$, com a invasão vascular $(p=0,0002)$, com a pouca diferenciação celular $(p=0,0001)$ e as metástases a distância $(p=0,0001)$. Como conclusão eles afirmam que a mortalidade global e o risco de metástases aumentam com a profundidade da neoplasia.

Conforme descrito anteriormente, a recidiva tumoral ocorreu em $32,4 \%$ dos casos e na taxa de sobrevida global esse foi o fator de pior prognóstico. Em série publicada pela Mayo Clinic, Taylor et al. ${ }^{88}$ relataram recidiva tumoral em $30 \%$ dos pacientes submetidos a essas operações pretensamente curativas. Montesani et al ${ }^{89}$ compararam a taxa de recidiva loco - regional em operações-padrão oncológica e nas operações alargadas, obtendo índices de $13 \%$ e $26 \%$ respectivamente.

No trabalho de Yun et al ${ }^{63}$ detectaram-se recidivas tumorais predominantemente distantes do tumor primário, assim como na presente série, em que $70 \%$ delas foram assim classificadas. Em tumores colônicos sabe-se que a recorrência local é incomum, ao passo que nos retais a 
recorrência local ou pélvica pode acontecer em mais de $20 \%$ dos casos. O sítio mais freqüente de metástases é o fígado que contribui com dois terços das recorrências, quer sejam únicas e isoladas, ou disseminadas em outros locais como pulmão, abdominal (extra-hepática), ossos e cérebro ${ }^{76}$.

Em trabalho prospectivo, Andreoni et al ${ }^{84}$ analisaram 902 pacientes não selecionados e observaram resultados de morbi-mortalidade perioperatória, sobrevida global e recorrência em seguimento de oito anos. A evolução dos doentes permitiu ressaltar as diferenças consideráveis de prognóstico entre o câncer do cólon e do reto quando analisados individualmente, destacando o maior potencial de disseminação loco regional dos tumores retais. Além disso, destacam que a ocorrência de metástases à distância no câncer de cólon e reto foi semelhante ${ }^{90}$. Já a recorrência local foi significativamente mais comum no câncer de reto, associado ou não com a metástase à distância.

No presente estudo, os fatores associados com menor sobrevida e pior prognóstico foram a localização retal do tumor (em contraposição às neoplasias no cólon), a profundidade da lesão (T4 pior que T3), a ocorrência de invasão vascular, linfática e perineural e a presença de linfonodos comprometidos pela neoplasia.

Assim, os tumores colorretais localmente avançados constituem um subgrupo distinto em que pode ocorrer invasão por contigüidade sem a presença de doença à distância, tornando-os passíveis de ressecção curativa. Ao contrário do que se poderia supor um maior número de órgãos removidos não influencia negativamente os índices de sobrevida. Apesar da 
elevada morbidade operatória eventualmente associada aos procedimentos de maior porte, o tratamento desses tumores com a inclusão de outras vísceras ou estruturas constitui a maneira mais adequada para se obter a cura dos pacientes nessa situação, podendo propiciar alívio sintomático e algum benefício de sobrevida até mesmo em situações paliativas.

A realização de operações alargadas para se atingir a completa ressecção do tumor pode vir no contexto de uma decisão intra-operatória, que deve contemplar o risco de complicações e o potencial de sobrevida em cada caso. Desta forma, o reconhecimento de fatores de risco que podem influenciar a possibilidade de cura de cada paciente assume um papel de destaque nas decisões e na estimativa de prognóstico individual.

Apesar da instituição de terapia adjuvante multimodal, os altos índices de recidiva local após ressecções multiviscerais em tumores retais ainda representam um problema que invoca a necessidade de controlar de maneira mais efetiva a doença avançada na região pélvica.

Esses dados ressaltam a importância de se estabelecer o diagnóstico do CCR em fase mais precoce possível. Nesse contexto, recomenda-se a realização de colonoscopia após os 50 anos de idade e a pesquisa de sangue oculto nas fezes anualmente para pessoas com risco médio, podendo-se antecipar o rastreamento nos indivíduos com antecedentes familiares ou suspeita de CCR hereditário ${ }^{5,6}$. Mais recentemente, tem sido destacado o papel dos hábitos individuais como fatores de risco, podendo modificar a forma e os critérios de rastreamento populacional ${ }^{91}$. 


\section{Conclusões}


Nas condições da presente pesquisa, que avaliou as ressecções colorretais alargadas realizadas em período de 12 anos, pode-se concluir que:

1. Detectaram-se tumores colorretais localmente avançados em $13,2 \%$ dos pacientes operados;

2. O intestino delgado, a bexiga e o útero foram os órgãos mais freqüentemente ressecados em monobloco com o tumor primário;

3. Ocorreram complicações operatórias em $25 \%$ dos doentes, e foi necessário realizar transfusão sangüínea em quase metade dos pacientes operados;

4. A sobrevida dos pacientes submetidos a operações curativas sofreu impacto negativo na presença de maior penetração na parede, invasão vascular, linfática e perineural, nos tumores de localização retal e naqueles com linfonodos comprometidos;

5. Outras variáveis como tipo histológico, grau de diferenciação tumoral, número de órgãos ressecados, transfusão de sangue e caráter das aderências entre órgãos não influenciaram as chances de sobrevida. 


\section{Referências}


1. Cunha AC, Freddi MJAL, Crestana MF, Aragão MS, Cardoso SC, Vilhena V. Guia de apresentação de dissertações, teses e monografias. $2^{\mathrm{a}}$ ed. - São Paulo: Serviço de Biblioteca e Documentação - 2005. 114 p. Polo Gráfica e Editora.

2. Ministério da Saúde - Brasil. Instituto Nacional do câncer. Estimativa 2008; Incidência de Câncer no Brasil. Rio de Janeiro. INCA 2008.

3. Jemal A, Murray T, Wars E, Samuels A, Tiwari RC, Ghafoor A, Feuer EJ, Thun MJ. Cancer statistics 2005; CA Cancer J Clinic 2005; 55(1):10-30.

4. Rowe VL, Frost DB, Huang S. Extended resection of locally advanced colorectal carcinoma. Ann Surg Oncol 1997;4:131-36.

5. Campos FG, Habr-Gama A, Perez RO, Seid VE, Alves PRA. Prevenção e rastreamento do câncer colorretal. Atualização em cirurgia do aparelho digestivo e coloproctologia - Gastrão 2008; ed. TecArt; pg. 249-60.

6. Habr-Gama A, Campos FG. Rastreamento e vigilância no câncer colorretal. Endoscopia Digestiva Diagnóstica e Terapêutica 2005; ed. Revinter; 58:509-20.

7. Vargas C. Câncer colorretal avançado - tópicos de interesse do endoscopista. Endoscopia Digestiva Diagnóstica e Terapêutica 2005; ed. Revinter; 61:538-49. 
8. Campos FGM, Waitzberg DL, Waitzberg AFL, Habr-Gama A, Kiss DR, Gama Rodrigues J. Diet and colorectal cancer: current evidence for etiology and prevention. Nutr Hosp 2005;20(1):25.

9. Kushi L, Giovannucci E. Dietary fat and cancer. Am J Med 2002;113:63S-70S.

10. Chammas R, Novak EM. Mecanismos de invasão e metástases em câncer colorretal. Câncer de Cólon, Reto e Ânus 2005; ed. Lemar/Tecmedd; 4:55-62.

11. Araújo SEA, Imperiale AR, Haddad L, Ferreira AV, Campos FGM, Nahas CSR, Sobrado Junior CW, Habr-Gama A, Kiss DR, Rodrigues JG. Resultados das operações com ressecção alargada em 46 pacientes com câncer colorretal. Rev Bras Coloproct 2004;24(2):131-6.

12. Cianchi F, Messerini L, Palomba A, Boddi V, Perigli G, Pucciani F, Bechi $\mathrm{P}$, Cortesini C. Character of the invasive margin in colorectal cancer. Does it improve prognostic information of dukes staging? Dis Col Rectum 1997;40(10):1170-6.

13. Campos FG. In: Habr-Gama A, Gama-Rodrigues J, Machado MCC, Cecconello I, Zilberstein B, Saad WA, Bresciani C. Câncer no reto variáveis importantes na decisão pré-operatória. Atualização em cirurgia do Aparelho Digestivo e em Coloproctologia - Gastrão. São Paulo. Ed. Frôntis 2002; p. 249-62.

14. Campos FGM, Habr-Gama A, Alves PRA, Silva JH, Souza Junior AFS, Nahas SC, Pinotti WH. Carcinomas colo-retais sincrônicos. Rev Bras Coloproct 1995; 15(1):19-24. 
15. Lehnert T, Methner M, Pollok A, Schaible A, Hinz U, Herfarth C. Multivisceral resection for locally advanced primary colon and rectal cancer in analysis of prognostic factor 201 patients. Ann Surg 2002;235:217-25.

16. Metzer U, Gross TH, Honogger HP. Adjuvant treatment for colorectal cancer: "State of the art", messages from recent trials. Eur J Surg Oncol 1995;21:341-6.

17. Sugarbaker ED. Coincident removal of additional structures in resections for carcinoma of the colon and rectum. Ann Surg 1946:123:1036-46.

18. Vieira RAC, Lopes A, Almeida PAC, Rossi BM, Nakagawa WT, Ferreira FO, Melo CA. Prognostic factors in locally advanced colon cancer treated by extended resection. Rev Hosp Clin Fac Med S Paulo 2004;59(6):361-8.

19. Bowne WB, Lee B, Wong WD, Bem-Porat Leah, Shia J, Cohen AM, Enker WE, Guillen JG, Paty PB, Weiser MR. Operative salvage for locoregional recurrent colon cancer after curative resection: an analysis of 100 cases. Dis Col Rectum 2005;48(5):897-909.

20. Kelley WE, Brown PW, Lawrence WJr, Terz JJ. Penetrating, obstructing, and perforating carcinoma of the colon and rectum. Arch Surg 1981;116:381-4.

21. Silva JH, Dainesi MA, Paranaguá D, Formiga GJS. Ressecção alargada para o câncer colorretal. Rev Bras Coloproct 1993;13(2):35-7.

22. Reinbach DH, Gregor MC, Murray GD, Odwyes PJ. Effect of the surgeon's specialty interest on the type of resection performed for colorectal cancer. Dis Col Rectum 1994;37:1020-23. 
23. Aleksic M, Hennes N, Ulric B. Surgical treatment of locally advanced rectal cancer. Dis Surgery 1998; 15:342-6.

24. Gall FP, Tonak Altendorf A. Multivisceral resection in colorectal cancer. Dis Col Rectum 1987;30:337-41.

25. Pittan MR, Thornton $\mathrm{H}$, Ellis $\mathrm{H}$. Survival after extended resection for locally advanced carcinomas of the colon and rectum. Ann $R$ Coll Surg Engl 1984;66:81-4.

26. Platell CFE, Semmens JB. Review of survival curves for colorectal cancer. Dis Col Rectum 2004;47(12):2070-75.

27. Barbosa-Silva T, Carvalho EES, Campos JEGO, Silva RG, Conceição AS, Lacerda-Filho A. Ressecção alargada em pacientes com câncer colorretal localmente invasivo. Rev Bras Coloproct 2002;22(1):27-32.

28. Eisemberg SB, Kraybill WG, Lopez MJ. Long-term results of surgical resection of locally advanced colorectal carcinoma. Surgery 1990;108:779-86.

29. Eldar S, Kemeny MM, Terz JJ. Extended resections for carcinoma of the colon and rectum. Surg Gynecol Obstet 1985;161:319-22.

30. Hunter JA, Ryan SP. En-bloc resection of colon cancer adherent to other organs. Am J Surg 1987;154:67-70.

31. Izbick JR, Hosh SB, Knoefel WT, Plaslick B, Bloechle C, Broelsch CE. Extended resections are beneficial for patients with locally advanced colorectal cancer. Dis Col Rectum (hist arch)1995;38(12):1251-6. 
32. McGlone TP, Bernie WA, \& Elliot DW. Survival following extended operations for extracolonic invasion by colon cancer. Arch Surg 1982;117:595-99.

33. Taylor WE, Donohue JH, Gunderson LL, Nelson H, Nagorney DM, Devine RM, Haddock MG, Larson DR, Rubin J, O'Connell MJ. The Mayo Clinic experience with multimodality treatment of locally advanced or recurrent colon cancer. Ann Surg Oncol 2001;9(2):177-85.

34. Vitelli CE, Crenca F, Fortunato L, Di Nardo A, Farina M, Mustacciuoli G. Pelve exenterative procedures for locally advanced or recurrent colorectal carcinoma in a community hospital. Techn Coloproct 2003;7(3):159-63.

35. Harish K, Narayanaswamy YV, Nirmala S.Treatment outcomes in locally advanced colorectal carcinoma. Int Semin Surg Oncol 2004;1:1-8.

36. Lopez MJ, Monafo WW. Role of extended resection in the initial treatment of locally advanced colorectal carcinoma. Surgery 1993; 113(4):365-72.

37. Govindarajan A, Coburn NG, Kiss A, Rabeneck L, Smith AJ, Law CHL. Population-based assessment of the surgical management of locally advanced colorectal cancer. JNCI 2006;98(20):1474-81.

38. Moyniham B. Abdominal operations. Philadelphia: Sauders, 1926.

39. Fleming ID, Cooper JS, Henson DE, Hutter RV, Kennedy BJ, Murphy GP,et al,editors. AJCC cancer staging manual. $5^{\mathrm{a}}$ ed. Philadelphia (PA):Lippincott-Raven;1997. 
40. Fisher RA. Statistical methods for research workers. (13 ${ }^{a}$ ed), New York 1958.

41. Kaplan EL, Meier P. Nonparametric estimation from incomplete observation. J Am Stat Ass 1958;53:457-81.

42. Cox D. Regression models and life-tables. Journal of the Royal Statistical Society B 1972;34:187-220.

43. Tsodikov A. Semi-parametric models of long- and short-term survival: an application to the analysis of breast cancer survival in Utah by age and stage. Stat in Med 2002;21:895-920.

44. Tsodikov A, Ibrahim J, Yakovlev A. Estimating cure rates from survival data: an alternative to two-component mixture models. J Am Stat Ass 2003;98(464):1063-78.

45. Habr-Gama A, Souza PMSB, Ribeiro Jr. U, Nadalin W, GansI R, Sousa Jr. AHS, Campos FGM, Gama Rodrigues J. Low rectal cancer. Dis Col Rectum 1998;(41):1087-96.

46. Robbins \& Cotran. Patologia 2005; pg. 908.

47. Habr-Gama A, Campos FGM, Pinotti HW. Cirurgia alargada para o câncer no reto. Arq Bras Cir Dig 1990; 5(1):76-8.

48. Curley SA, Carlson GW, Shumate CR, Wishnow KI, Ames FC. Extended resection for locally advanced colorectal carcinoma. Am J Surg 1992;163(6):553-9. 
49. Lee SI, Park TA, Sohn SK. A survey on the impact of operation volume on rectal cancer management. J Korean Med Sci 2007;22(Suppl):S8690.

50. Farhoud S, Bromberg SH, Barreto E, Godoy AC. Variáveis clínicas e macroscópicas que influenciam o prognóstico do carcinoma colorretal. Arq Gastroenterol 2002;39(3):163-72.

51. Brandão O, Sobrinho-Simões $M A$, Serrão $D$, Moutinho-Ribeiro $M$, Azevedo C. Prognosis in colorectal carcinoma: a reassessment of the pathologist's role. Pathol Res Pract 1985; 180:506-10.

52. Hermanek P, Wiebelt H, Staimmer D, Riedl S. Prognostic factors of rectum carcinoma - experience of the German Multicentre Study SGCRC. German Study Group Colo-Rectal Carcinoma. Tumori 1995;81(3 Suppl):60-4.

53. Steinberg SM, Barwick KW, Stablein DM. Importance of tumor pathology and morphology in patients with surgically resected colon cancer. Cancer 1986;58:1340-5.

54. Guerra MR, Gallo CVM, Silva-Mendonça GA. Risco de câncer no Brasil: tendências e estudos epidemiológicos mais recentes. Rev Bras de Cancerol 2005;51(3):227-34.

55. Gebhardt C, Meyer W, Ruckriegel S, Meier U. Multivisceral resection of advanced colorectal carcinoma. Langenbeck's Arch Surg 1999;384:194-9.

56. Lopez MJ, Luna-Pérez P. Composite pelvic exenteration: is it worthwile? Ann Surg Oncol 2004;11:27-33. 
57. Meguid RA, Slidell MB, Wolfgang CL, Chang DC, Ahuja N. Is there a difference in survival between right - versus left - sided colon cancers? Ann Surg Oncol 2008;15(9):2388-94.

58. Dulk M, Marijnen CAM, Putter H, Rutten HJT, Beets GL, Wiggers $T$, Nagtegaal ID, Velde CJH. Risk factors for adverse outcome in patients with rectal cancer treated with an abdominoperineal resection in the total mesorectal excision trial. Ann Surg 2007;246(1):83-90.

59. Franko J, Gusani NJ, Holtzman MP, Ahrendt SA, Jones HL, Zeh HJ $3^{\text {rd }}$, Bartlett DL. Multivisceral resection does not affect morbidity and survival after cytoreductive surgery and chemoperfusion for carcinomatosis from colorectal cancer. Ann Surg Oncol 2008;15(11):3065-72.

60. Nakafusa Y, Tanaka M, Kitajima Y, Sato S, Miyazaki K. Comparison of multivisceral resection and standard operation for locally advanced colorectal cancer: analysis of prognostic factors for short-term and longterm outcome. Dis Col Rectum 2004;47(12):2055-63.

61. Nelson H, Petrelli N, Carlin A, Couture J, Fleshman J, Guillen J, Miedema B, Ota D, Sargent D. Guidelines 2000 for colon and rectal cancer surgery. JNCI 2001;93(8):583-96.

62. Perez RO, Bresciani BH, Bresciani C, Proscurshim I, Kiss D, GamaRodrigues J, Pereira DD, Rawet V, Cecconello I, Habr-Gama A. Mucinous colorectal adenocarcinoma: influence of mucin expression (Muc1,2 and 5) on clinico-pathological features and prognosis. Int $\mathrm{J}$ Colorect Dis 2008; 1-19.

63. Yun SH, Yun RH, Lee WS, Cho YB, Lee WY, Chun HK. The clinical outcome and prognostic factors after multivisceral resection for advanced colon cancer. Eur J Surg Oncol 2008;01:024. 
64. Bonfanti G, Bozzetti F, Docci R, Baticci F, Marolda R, Bignami P, et al. Results of extended surgery for cancer of the rectum and sigmoid. $\mathrm{Br} \mathrm{J}$ Sur 1982;69:305-7.

65. Polk HCJr. Extended resections for selected adenocarcinomas of the large bowel. Ann Surg 1972;175:892-9.

66. Spratt JS \& Spjut HJ. Prevalence and prognosis of individual clinical and pathological variables associated with colorectal carcinoma. Cancer 1967;20:1976-85.

67. Butcher HR \& Spjut HJ. Evaluation of pelvic exenteration for advanced carcinoma of lower colon. Cancer 1959;12:681-7.

68. Gentil FC, Lopez A, Sé AOS, Cavalcanti SF, Garcia SZ, Lima EWL, et al. Ressecção ampliada no tratamento do câncer avançado do cólon. Rev Bras Coloproct 1989;3:93-101.

69. Wong SKC, Jalaludin BB, Henderson CJA, Morgan MJ, Berthelsen AS, Issac MM, Kneebone A. Direct tumor invasion in colon cancer: correlation with tumor spread and survival. Dis Col Rectum 2008;51:1331-38.

70. Dukes CE. The classification of cancer of the rectum. J Pathol Bacteriol 1932;35:323-32.

71. Simpson WC, Mayo CW. The mural penetration of the carcinoma cell in the colon: anatomic and clinical study. Surg Gynecol Obstet 1930;68:872-77. 
72. Chang GJ, Rodriguez-Bigas MA, Skibber JM, Moyer VA. Lymph node evaluation and survival after curative resection of colon cancer: systematic review. JNCI 2007;99(6):433-41.

73. Johnson CD, Chen MH, Toledano AY, Heiken JP, Dachman A, Kuo MD, Menias CO, Siewert B, Cheema JI, Obregon RG, Fidler JL, Zimmerman P, Horton KM, Coakley K, lyer RB, Hara AK, Halvorsen RAJr, Casola G, Yee J, Herman BA, Burgart LJ, Limburg PJ. Accuracy of CT colonography for detection of large adenomas and cancers. $N$ Engl J Med 2008;359(12):1207-17.

74. Le Voyer TE, Sigurdson ER, Hanlon AL, Mayer RJ, Macdonald JS, Catalano PJ, Haller DG. Colon cancer survival is associated with increasing number of lymph nodes analyzed: a secondary survey of intergroup trial INT - 0089. J Clin Oncol 2003;21(15):2912-19.

75. Poeze M, Houbiers IGA, van de Velde GJH, Wabbes TH, Von Meyenfeldt MF. Radical resection of locally advanced colorectal cancer. Br J Surg 1995;82:1386-90.

76. Desch CE, Benson III AIB, Somerfield MR, Flynn PJ, Krause C, Loprinzi CL, Minsky BD, Pfister DG, Virgo KS, Petrelli NJ. Colorectal cancer surveillance: 2005 update of an American Society of Clinical Oncology Practice Guideline. J Clin Oncol 2005;23:8512-19.

77. Tepper JE. Reflections in rectosigmoid: retro-peritoneal vs. intraperitoneal. Int J Radiat Oncol Biol Phys 1988;14:1043-6.

78. Guillen JG, Chessin DB, Shia J, et al. A prospective pathological analysis using whole-mount sections of rectal cancer following preoperative combined modality therapy: implications for sphincter preservation. Ann Surg 2007;245:88-93. 
79. Guillen JG. Extended perineal resection of distal rectal cancers: surgical advance, increased utilization of neoadjuvant therapies, proper patient selection or all of the above ? J Clin Oncol 2008;26(21):3481-2.

80. West NP, Finan PJ, Anderin C, et al. Cylindrical abdominoperineal excision for low rectal cancer: evidence of its oncological superiority. $J$ Clin Oncol 2008;26:3517-22.

81. Marusch F, Koch A, Schimidt U, Zippel R, Gastmeier J, Ludwig K, GeiBler S, Pross M, Gastinger I, Lippert H. Impact of age on the shortterm postoperative outcome of patients undergoing surgery for colorectal carcinoma. Int J Colorect Dis 2002;17(3):177-84.

82. Marusch F, Koch A, Schimidt U, Steinert R, Ueberrueck T, Bittner R, Berg E, Engemann R, Gellert K, Arbogast R, Köckerling F, Gastinger I, Lippert $\mathrm{H}$. The impact of the risk factor "age" on the early postoperative results of surgery for colorectal carcinoma and its significance for Perioperative management. World J Surgery 2005;29(8):1013-22.

83. Jeekel J. Can radical surgery improve survival in colorectal cancer? World J Surg (hist arch) 1987;11(4):412-7.

84. Andreoni B, Chiappa A, Bertani E, Bellomi M, Orecchia R, Zampino M, Fazio N, Venturino M, Orsi F, Sonzogni A, Pace U, Monfardini L. Surgical outcomes for colon and rectal cancer over a decade: results from a consecutive monocentric experience in 902 unselected patients. World $\mathrm{J}$ Surg Oncol 2007;5(73)1-10.

85. Clavien PA, Sanabria JR, Strasberg SM. Proposed classification of complications of surgery with examples of utility in cholecystectomy. Surgery 1992;111:518-26. 
86. Paulson CE, Mitra N, Sonnad S, Armstrong K, Wirtalla C, Kelz RR, Mahmoud NN. National Cancer Institute designation predicts improved outcomes in colorectal cancer surgery. Ann Surg 2008;248(4):675-86.

87. Orkin BA, Dozois RR, Beart RWJr, Patterson DE, Gunderson LL, Ilstrup DM. Extended resection for locally advanced primary adenocarcinomas of the rectum. Dis Col Rectum 1989;32:286-92.

88. Taylor WE, Donohue JH, Gunderson LL, Nelson H, Nagorney DM, Devine RM, Haddock MG, Larson DR, Rubin J, O'Connell MJ. The Mayo Clinic experience with multimodality treatment of locally advanced or recurrent colon cancer. Ann Surg Oncol 2001;9(2):177-85.

89. Montesani C, Ribotta G, De Milito R, Pronio A, D’Amato A, Narilli P, Jaus M. Extended resection in the treatment of colorectal cancer. Int $\mathrm{J}$ Colorect Dis 1991;6:161-4.

90. Nagtegaal ID, van de Velde CJH, Marijnen CAM, et al. Low rectal cancer: a call for a change of approach in abdominoperineal resection. J Clin Oncol 2005;23:9257-64.

91. Acott AA, Theus SA, Marchant-Miros KE, Mancino AT. Association of tobacco and alcohol use with earlier development of colorectal cancer: should we modify screening guidelines? Am J Surg 2008;196(6):915-919. 